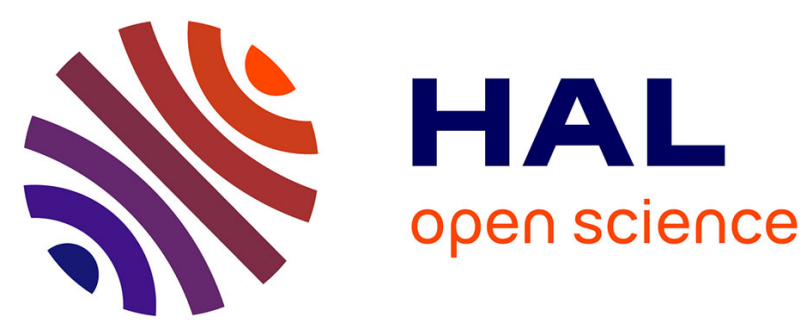

\title{
Bidimensional phases in Co-Pt surface alloys: A theoretical study of ordering and surface segregation
}

Alexis Front, Bernard Legrand, Guy Tréglia, Christine Mottet

\section{To cite this version:}

Alexis Front, Bernard Legrand, Guy Tréglia, Christine Mottet. Bidimensional phases in Co-Pt surface alloys: A theoretical study of ordering and surface segregation. Surface Science: A Journal Devoted to the Physics and Chemistry of Interfaces, 2019, 679, pp.128-138. 10.1016/j.susc.2018.08.024 . hal03547785

\section{HAL Id: hal-03547785 \\ https://hal.science/hal-03547785}

Submitted on 28 Jan 2022

HAL is a multi-disciplinary open access archive for the deposit and dissemination of scientific research documents, whether they are published or not. The documents may come from teaching and research institutions in France or abroad, or from public or private research centers.
L'archive ouverte pluridisciplinaire HAL, est destinée au dépôt et à la diffusion de documents scientifiques de niveau recherche, publiés ou non, émanant des établissements d'enseignement et de recherche français ou étrangers, des laboratoires publics ou privés. 


\title{
Bidimensional phases in Co-Pt surface alloys: A theoretical study of ordering and surface segregation
}

\author{
Alexis Front ${ }^{\mathrm{a}}$, Bernard Legrand ${ }^{\mathrm{b}}$, Guy Tréglia ${ }^{\mathrm{a}}$, Christine Mottet ${ }^{*, \mathrm{a}}$ \\ a Aix-Marseille Université, CNRS, CINAM UMR 7325, Campus de Luminy, 13288 Marseille, France \\ ${ }^{\mathrm{b}}$ DEN-SRMP, CEA, Université Paris-Saclay, F91191 Gif-sur-Yvette Cedex, France
}

\section{A R T I C L E I N F O}

\section{Keywords:}

Alloys surfaces

Nanoalloys

Surface segregation

Chemical ordering

Monte Carlo simulations

\begin{abstract}
A B S T R A C T
Surface segregation and bulk ordering are characterized by Monte Carlo simulations using a Tight-Binding interatomic potential within the Second Moment Approximation of the density of states (TB-SMA potential) which reproduces the bulk ordered phases and the surface segregation reversal between the dense (111) and (100) surfaces (Pt segregation) and the more opened (110) one (Co segregation). Among the different surface superstructures, most are simply the surface termination of bulk ordered phases and have been observed experimentally, but we predict also purely bidimensional phases such as the $(\sqrt{3} \times \sqrt{3}) \mathrm{R} 30(111)$ or the $\mathrm{c}(2 \times 2)(110)$ ones with no equivalence in the bulk alloy. Such $(\sqrt{3} \times \sqrt{3}) \mathrm{R} 30(111)$ phase should be stable on nanoalloys where the (111) facets are prevailing. Finally, we show that the $c(2 \times 2)$ superstructure of the CoPt $(100)$ surface, which represents the mixed variant of the $\mathrm{L} 1_{0}$ phase, remains stable above the bulk order/disorder critical temperature.
\end{abstract}

\section{Introduction}

Since the compilation of the thermodynamic properties of binary alloys written by Hultgren et al. in 1981 [1], there have been a lot of studies performed on the Co-Pt bulk phase diagram in the eighties [2-4] up to the beginning of the 21st century [5-8]. More recently, a review on Co-Pt nanoalloys [9] shows the huge amount of experimental and theoretical works on Co-Pt-based nanostructures. Such interest is due to the magnetic and catalytic properties of this alloy under the shape of nanoparticles. Indeed, small magnetic nanoparticles consist in a single magnetic domain which can be viewed as a macrospin and measured on individual nanoparticles [10], giving rise to potential applications in ultra-high density data storage, where CoPt nanoparticles as FePt ones are furthermore able to maintain their magnetization thanks to their high magneto-crystalline anisotropy [11-13]. This anisotropy competes with superparamagnetism effect leading to the fluctuation of the magnetic moment orientation with the temperature as described by the Néel-Brown model. The other interest comes from the electrocatalytic properties in fuel cells. It has been shown that Co-Pt system presents higher activity in the electrochemical oxygen reduction reaction as compared to pure Pt. Furthermore, the $\mathrm{L} 1_{0}$ ordered phase of the CoPt alloys has been measured to be seven times more active than the A1 disordered alloy [14].

Knowing the strong relationship between structure and properties, it is crucial to know and control the atomic structure and chemical redistribution of the different metal species in the core and at the surface of the nanoparticles. Therefore, there have been a lot of experimental [15-25] and theoretical [26-31] investigations to characterize the atomic structure and chemical ordering in Co-Pt nanoalloys. From a theoretical point of view, fully $a b$ initio methods are too heavy to be implemented for large systems and even density functional theory (DFT) calculations, which can treat larger systems because of their approximation concerning the treatment of exchange-correlation features, are limited in the exploration of the configurations space. However they can give reliable results as reference for relatively small systems [26-28]. Statistical methods such as Monte Carlo simulations using Tight-Binding Ising model [30] or Cluster Expansion method [31] suffer from a rigid lattice approximation even if the cluster expansions obtained from first principle calculations are initially relaxed. An other approach to couple atomic relaxation and chemical ordering is to build interatomic potentials.

There exists only a few interatomic potentials for Co-Pt systems in the literature [32-34] with one developed within the Embedded Atom Method [35] and the other two within the second moment approximation in the Tight Binding framework [36]. We used the last one to study the structure and chemical ordering in CoPt nanoalloys [16,20,29,34]. However, this parameterization, focused on the equiconcentration, took into account neither the asymmetry of the

\footnotetext{
* Corresponding author.

E-mail address: mottet@cinam.univ-mrs.fr (C. Mottet).
} 
phase diagram nor the experimental reversal in surface segregation as a function of the orientation.

To correct these drawbacks we build a new interatomic potential for Co-Pt systems and test it on the bulk alloy phase diagram and on the segregation profiles for the three low indices surfaces. In particular, for the Co-Pt system, similarly with the well studied Pt-Ni one, a surface segregation reversal is observed experimentally between the more compact surfaces, the (111) and (100) surfaces, where Pt segregates [37-42] and the (110) one where Ni [43] or Co [44,45] segregates forming a sandwich structure with oscillating profile. Many questions arise concerning the competition or synergy between the surface segregation of one species and the chemical ordered phases coming from the bulk. These questions are even more complex inside a nanoparticle where different facets with different orientations coexist in the same system [46]. The theoretical description of the structures for semi-infinite systems with (111), (100) and (110) surfaces as a function of temperature and concentration will help to the understanding of the structures of finite nanoalloys. In particular, we characterize a well defined 2D surface alloy with the $(\sqrt{3} \times \sqrt{3})$ R30(111) which has no equivalence in the bulk, and which is mainly observed in intermetallic systems with strong ordering and surface segregation tendencies: $\mathrm{Sn} / \mathrm{Cu}$ (111) [47], Al/Cu(111) [48,49], Sn/Pt(111) [50,51], Sn/Ni(111) [52] or $\mathrm{Te} / \mathrm{Cu}(111)$ [53]. Such $(\sqrt{3} \times \sqrt{3}) \mathrm{R} 30(111)$ has also been observed on immiscible systems like $\mathrm{Bi} / \mathrm{Cu}(111)$ [54,55], $\mathrm{Bi} / \mathrm{Ag}(111)$ [56], $\mathrm{Pb} / \mathrm{Ni}$ (111) [57] and $\mathrm{Pb} / \mathrm{Ag}(111)$ [58-60]. In theory, we already obtained this surface chemical ordering on the (111) facets of Pd-Au nanoalloys [61], which was never pointed out before on nanoalloys. We predict the same 2D phases on the (111) facets of Co-Pt nanoalloys, which was not stabilized using on-lattice Ising model [30] or cluster expansion method [31]. We can guess that atomic relaxations and strain effects could have an influence on the stabilization of this $2 \mathrm{D}$ surface superstructure.

Our theoretical study is based on a semi-empirical Tight-Binding interatomic potential fitted to $a b$-initio calculations and experimental data. Numerical simulations are performed using Monte Carlo simulations in canonical and semi-grand canonical ensemble in order to describe systems at a given concentration (canonical) or at a given difference of chemical potential (semi-grand canonical) enabling to vary the concentration and temperature to describe phase diagrams.

The paper is devised in five parts including introduction and conclusion. The second part gives a description of the theoretical energetic model and atomistic simulations. The third and fourth parts describe the results respectively on the bulk and on the surfaces.

\section{Energetic model and Monte Carlo simulations}

We use Monte Carlo simulations in canonical and semi-grand canonical ensemble in order to characterize bulk and surface equilibrium phases along the whole range of concentration $c$ in the $\mathrm{Co}_{1-c} \mathrm{Pt}_{c}$ alloys from pure $\mathrm{Co}(\mathrm{c}=0)$ to pure $\mathrm{Pt}(\mathrm{c}=1)$. The energetic model is a many-body interatomic potential based on a Tight Binding model in the framework of the second moment approximation of the density of states (TB-SMA) for transition metals, fitted to ab-initio calculations in the density functional theory (DFT). The potential is also fitted in order to reproduce experimental results such as the order/disorder critical temperatures for Co-Pt bulk alloys and the surface segregation for low indices surfaces.

\subsection{Interatomic many-body potential in the TB-SMA approximation}

The energetic model is a semi-empirical many-body potential derived from the density of states of the d-band metals (transition metals) approximated to its second moment (width of the d-band) in the tight binding framework [36]. It leads to an attractive term with a square root dependence on the coordination number:
$E_{i}^{\text {band }}=-\sqrt{\sum_{j, r_{i j}<r_{a b}^{c}} \xi_{a b}^{2} e^{-2 q_{a b}\left(\frac{r_{i j}}{r_{a b}^{0}}-1\right)}}$

for the band term at site $i . a, b=(\mathrm{A}, \mathrm{B})$ are the nature of the metal atom. $r_{i j}$ is the distance between the atom at site $i$ and one neighbor at site $j, r_{a b}^{c}$ is the cut-off distance and $r_{a b}^{0}$ is the first-neighbor distance depending on the nature of the atoms. A repulsive term of Born-Mayer type is added to simulate the core repulsion:

$E_{i}^{r e p}=\sum_{j, r_{i j}<r_{a b}^{c}} A_{a b} e^{-p_{a b}\left(\frac{r_{i j}}{r_{a b}^{0}}-1\right)}$.

The homoatomic parameters $p_{a b}, q_{a b}, A_{a b}, \xi_{a b}$ with $a=b$ are fitted to the cohesive energies, lattice parameters and elastic constants. The two elements have been stabilized in the fcc structure which is natural for Pt but not for Co which is hcp in bulk. The justification for Co is that when alloyed with Pt, the structure becomes fcc in the major part of the concentration range. The hcp structure with the present TB-SMA potential presents an energy excess of $30 \mathrm{meV} /$ at. for Co with a $=2.54$ Åand $\mathrm{c}=4.14 \AA$, and of $10 \mathrm{meV} / \mathrm{at}$. for Pt with $\mathrm{a}=2.81$ Åand $\mathrm{c}=$ $4.60 \AA$. The vacancy energy calculated within the present potential is equal to $1.5 \mathrm{eV}$ for Co and $1.61 \mathrm{eV}$ for Pt which are in good agreement with experimental results [62] giving $135 \mathrm{KJ} /$ mole $(1.4 \mathrm{eV})$ for Co and $160 \mathrm{KJ} / \mathrm{mole}(1.66 \mathrm{eV})$. In the Co case, we notice that the DFT calculation overestimates the absolute value of the cohesive energy in the face centered cubic (fcc) structure by more than $20 \%$ as compared to the experimental value in the hexagonal compact packing (hcp) structure since the hcp calculated energy should be even larger $(5.35 \mathrm{eV} / \mathrm{at}$. calculated in fcc structure compared to $4.45 \mathrm{eV} /$ at. in experiment with hcp structure). Better calculations including properly electronic correlations within the GGA + U approach reduce significantly the cohesive energy but too much since they underestimate the experimental value by $17 \%$ [63]. In this exceptional case, we preferred to fit the cohesive energy and lattice parameter of Co relatively to the ones of Pt, keeping roughly the same difference as compared to the experimental data. This is a way to respect the fact that for transition metals and noble metals the GGA functional has the tendency to overestimate slightly the lattice parameter (around 2\%) and to underestimate the cohesive energy (less than $10 \%$ ). Concerning the surface energies, the experimental value representing the average (100) surface shows that when expressed in J/ $\mathrm{m}^{2}$ the Pt has the lower surface energy as compared to Co but it is reversed when expressed in eV/at. In DFT, the Pt surface energies are always lower for any orientation and any units, which is in favor of the Pt surface segregation, as already obtained by Dannenberg et al. [64] and in agreement with the observed Pt surface segregation on (111) and (100) surfaces [38-42]. However, on the (110) orientation, the experiments show Co surface segregation $[44,45]$, which has been a strong constraint to be fulfilled by the present potential. This explains why the TB-SMA surface energies are rather very similar for Pt and Co (at least when expressed in $\mathrm{eV} /$ at.) whereas a slight discrepancy arises when expressed in $\mathrm{J} / \mathrm{m}^{2}$.

The heteroatomic parameters $(a \neq b)$ are fitted to the mixing energies calculated using the density functional theory (DFT-GGA/PW91) (see Tab. 3 and discussion in the following), and to experimental data such as the order/disorder critical temperatures $[1,4]$ of the bulk alloys and the surface segregation of alloys surfaces [38-45].

The TB-SMA parameters of the new potential are given on Table 2 together with the ones of the previous potential [33] for comparison. We notice that the parameters of the pure metals are lower in the new parameterization whereas the $A$ and $\xi$ of the mixed interactions are higher than in the old parameterization. This leads to an increase of the mixing enthalpy as compared to the experimental one, to which was fitted the old parameterization (see Fig. 1).

The DFT calculations are performed using the VASP code with the generalized gradient approximation (GGA) in the PW91 version [65] 


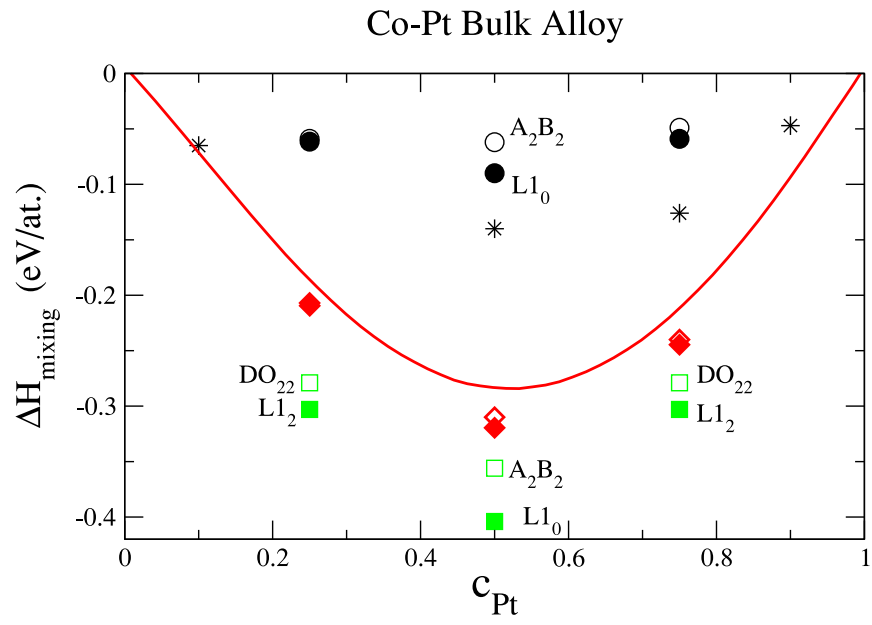

Fig. 1. Mixing enthalpies of the bulk Co-Pt alloys at stoichiometries $\mathrm{Co}_{3} \mathrm{Pt}$, CoPt and $\mathrm{CoPt}_{3}$ for the DFT calculations (black circles) at $0 \mathrm{~K}$, the experimental data [1] (black stars) at $900 \mathrm{~K}$ but still in the ordered phase $\left(\mathrm{T}_{c}\right.$ equal $1100 \mathrm{~K}$ for CoPt and $1000 \mathrm{~K}$ for $\mathrm{CoPt}_{3}$ and some extrapolated points at $\mathrm{c}_{P t}=0.1$ and 0.9 ), the TB-SMA potential (red diamonds) at $0 \mathrm{~K}$ and finally TBIM calculations at $0 \mathrm{~K}$ (green squares) used in ref. [30]. Full symbols represent the $\mathrm{L} 1_{0}$ and $\mathrm{L} 1_{2}$ phases whereas empty symbols represent the $\mathrm{DO}_{22}$ and $\mathrm{A}_{2} \mathrm{~B}_{2}$ phases. The curve (red line) represents the TB-SMA potential in the disordered state at $800 \mathrm{~K}$. (For interpretation of the references to colour in this figure legend, the reader is referred to the web version of this article.)

and the projector augmented wave (PAW) $[66,67]$ interaction potential between the ions and the electrons. The choice of the functional is crucial in DFT calculations and the GGA using either PW91 or PBE [68] functionals provide the best results among other functionals including meta-GGA and hybrid functionals as compared to experiments for what concerns structure and energy data $[69,70]$ and also for what concerns their surfaces [71] if we want to get both surface and bulk properties. The $s$ and $d$ valence electrons are considered for each metal with a cutoff energy equal to $600 \mathrm{eV}$ for plane wave basis set. The convergence criterion for electronic and ionic steps are respectively $10^{-6}$ and $10^{-5}$ $\mathrm{eV}$. The Brillouin zone integration is performed with the Monkhorst-Pack scheme with k-point mesh comprising 18 subdivisions along each reciprocal lattice vector for pure bulk calculations when reduced to a mesh of 4 atoms in the slab. This mesh is sufficient to calculate the cohesive energies of pure metals and alloys with simple $\mathrm{L} 1_{0}$ and $\mathrm{L} 1_{2}$ phases. When considering impurities in the bulk or at the surface, the slab is duplicated two times in $\mathrm{x}$ and $\mathrm{y}$ directions and three times in the $\mathrm{z}$ direction so that the k-point mesh is reduced to $9 \times 9 \times 6$ for impurities in bulk (48 atoms in the slab) and $9 \times 9 \times 1$ for impurities at surface (same slab with six "empty" layers in the $\mathrm{z}$ direction). The cohesive energy, lattice parameter and surface energy have been calculated for Co and Pt, using spin polarized calculations in the presence of Co (see the results in Table 1). The mixing enthalpies are defined as:

$\Delta H_{A_{n} B_{m}}^{\operatorname{mix}}=\frac{E_{A_{n} B_{m}}^{\text {slab }}-n E_{c o h}^{A}-m E_{c o h}^{B}}{n+m}$

as a function of the concentration $c=m /(n+m)$ and are reported in Table 3 and Fig. 1. It is worth noticing that magnetism is the driving force of the chemical ordering in CoPt alloys [72], which justifies that our model implicitely takes into account the magnetism of the system. The dissolution enthalpies correspond to the limit of the dissolution of one impurity whereas mixing enthalpies for $\mathrm{Co}_{3} \mathrm{Pt}$, CoPt and $\mathrm{CoPt}_{3}$ correspond to the formation energy of the compounds at $c=0.25$, $c=0.50$ and $c=0.75$. The dissolution enthalpy of $\mathrm{B}$ in a bulk of $\mathrm{A}$ is deduced from the calculation of the permutation enthalpie $\left(\Delta H_{A(B)}^{\text {perm }}\right)$ i.e. the energy of the large box (48 atoms with 47 of type A and one of type $B$ equivalent to the permutation of one atom of type A with an atom of
Table 1

DFT and TB-SMA calculations of the lattice parameters, cohesive energies, elastic constants and surface energies of the pure metals. Experimental values are taken from C. Kittel, Introduction to solid state physics, Wiley, New-York (1996), G. Simmons and H. Wang, Single crystal elastic constants and calculated aggregates properties, MIT, Cambridge (1971) and W.R. Tyson and W.A. Miller, Surf. Sci. 62, 267 (1977). The structure is fcc in general except for the experimental Co which is hcp.

\begin{tabular}{|c|c|c|c|c|c|c|c|c|}
\hline & $\begin{array}{l}\mathrm{a} \\
(\AA)\end{array}$ & $\begin{array}{l}E_{\text {coh }} \\
\text { (eV/at.) }\end{array}$ & B & $\begin{array}{l}\mathrm{c}_{44} \\
\text { (GPa) }\end{array}$ & $c^{\prime}$ & $\gamma^{111}$ & $\begin{array}{l}\gamma^{100} \\
(\mathrm{eV} / \\
\text { at. }) /(\mathrm{J} / \\
\left.\mathrm{m}^{2}\right)\end{array}$ & $\gamma^{110}$ \\
\hline \multicolumn{9}{|l|}{ Co } \\
\hline DFT-GGA/PW91 & 3.52 & -5.35 & & & & $\begin{array}{l}0.68 / / \\
2.03\end{array}$ & $\begin{array}{l}0.96 / \\
2.47\end{array}$ & $\begin{array}{l}1.31 / \\
2.40\end{array}$ \\
\hline DFT-GGA + U[63] & 3.55 & -3.79 & & & & & & \\
\hline TB-SMA & 3.60 & -4.90 & 196 & 88 & 26 & $\begin{array}{l}0.54 / \\
1.54\end{array}$ & $\begin{array}{l}0.67 / / \\
1.66\end{array}$ & $\begin{array}{l}1.00 / \\
1.75\end{array}$ \\
\hline Exp. (hcp) & 3.54 & -4.45 & 195 & 82 & - & - & $\begin{array}{l}1.00 / \\
2.59\end{array}$ & - \\
\hline \multicolumn{9}{|l|}{ Pt } \\
\hline DFT & 3.98 & -5.53 & & & & $\begin{array}{l}0.64 / \\
1.50\end{array}$ & $\begin{array}{l}0.91 / / \\
1.85\end{array}$ & $\begin{array}{l}1.31 / \\
1.87\end{array}$ \\
\hline TB-SMA & 3.98 & -5.53 & 203 & 105 & 37 & $\begin{array}{l}0.51 / / \\
1.20\end{array}$ & $\begin{array}{l}0.67 / / \\
1.36\end{array}$ & $\begin{array}{l}1.02 / \\
1.46\end{array}$ \\
\hline Exp. (fcc) & 3.92 & -5.86 & 288 & 77 & 52 & - & $\begin{array}{l}1.19 / \\
2.48\end{array}$ & - \\
\hline
\end{tabular}

Table 2

TB-SMA parameters: the parameters of the present study compared with the published ones [33].

\begin{tabular}{lllll}
\hline a-b & $\mathrm{P}_{a b}$ & $\mathrm{q}_{a b}$ & $\mathrm{~A}_{a b}$ & $\xi_{a b}$ \\
\hline Co-Co & 8.642 & 2.300 & 0.158 & 1.844 \\
Co-Co [33] & 8.80 & 2.96 & 0.189 & 1.907 \\
Pt-Pt & 10.796 & 3.198 & 0.199 & 2.232 \\
Pt-Pt [33] & 11.14 & 3.68 & 0.242 & 2.506 \\
Co-Pt & 9.719 & 2.749 & 0.275 & 2.488 \\
Co-Pt [33] & 9.97 & 3.32 & 0.245 & 2.386 \\
\hline
\end{tabular}

Table 3

Mixing enthalpies for concentred alloys or dissolution enthalpies in the diluted limits $\mathrm{Co}(\mathrm{Pt})$ and $\mathrm{Pt}(\mathrm{Co})$, and lattice parameters calculated by DFT-GGA/PW91, TB-SMA potential and experiments [1]. In the diluted limits, the lattice parameters are the ones of the pure metal and Co is considered in the fcc structure.

\begin{tabular}{llll}
\hline $\begin{array}{l}\Delta \boldsymbol{H}(\mathrm{meV}) \\
\text { lattice }(\AA)\end{array}$ & DFT-GGA/PW91 & TB-SMA & Experiment \\
\hline $\mathrm{Co}(\mathrm{Pt})$ & & & \\
& $\mathbf{- 8 4}$ & $\mathbf{- 8 4 4}$ & $\mathbf{- 6 5 0}$ \\
$\mathrm{Co}_{3} \mathrm{Pt}$ & $\mathrm{a}=3.52$ & $\mathrm{a}=3.60$ & $\mathrm{a}=3.54$ \\
& $\mathbf{- 6 2}$ & $\mathbf{- 2 1 0}$ & - \\
$\mathrm{CoPt}$ & $\mathrm{a}=3.67$ & $\mathrm{a}=3.79$ & $\mathrm{a}=3.66$ \\
& $\mathbf{- 9 0}$ & $\mathbf{- 3 2 0}$ & $\mathbf{- 1 4 0}$ \\
& $\mathrm{a}=3.83$ & $\mathrm{a}=3.93$ & $\mathrm{a}=3.793$ \\
& $\mathrm{c}=3.715$ & $\mathrm{c}=3.86$ & $\mathrm{c}=3.675$ \\
$\mathrm{CoPt}_{3}$ & $\mathrm{c} / \mathrm{a}=0.97$ & $\mathrm{c} / \mathrm{a}=0.98$ & $\mathrm{c} / \mathrm{a}=0.97$ \\
& $\mathbf{- 5 9}$ & $\mathbf{- 2 4 5}$ & $\mathbf{- 1 2 6}$ \\
$\mathrm{Pt}_{(\mathrm{Co})}$ & $\mathrm{a}=3.90$ & $\mathrm{a}=3.96$ & $\mathrm{a}=3.85$ \\
& $\mathbf{- 2 9 0}$ & $\mathbf{- 1 0 6 1}$ & $-\mathbf{4 7 0}$ \\
& $\mathrm{a}=3.98$ & $\mathrm{a}=3.98$ & $\mathrm{a}=3.92$ \\
\hline
\end{tabular}

type B) as compared to the one of the same box with only atoms of type A:

$\Delta H_{A(B)}^{\text {perm }}=E_{A_{n-1} B_{1}}^{\text {slab }}-E_{A_{n}}^{\text {slab }}$

Then the dissolution enthalpy $\Delta H^{\text {dis }}$ is equal to:

$\Delta H_{A(B)}^{\text {dis }}=\Delta H_{A(B)}^{\text {perm }}+\left(E_{c o h}^{A}-E_{c o h}^{B}\right)$

The mixing enthalpies presented on Table 3 and Fig. 1 show that the 
Table 4

Order/disorder critical temperatures obtained in our model as compared to the experimental ones $[1,2,4,5]$.

\begin{tabular}{llll}
\hline (in K) & $\mathrm{Co}_{3} \mathrm{Pt}$ & $\mathrm{CoPt}$ & $\mathrm{CoPt}_{3}$ \\
\hline TB-SMA & 450 & 540 & 500 \\
Exp. & 800 & 1100 & 1000 \\
\hline
\end{tabular}

DFT-GGA/PW91 using spin polarized calculations underestimate the mixing enthalpies of the Co-Pt alloys as compared to the experiments at $900 \mathrm{~K}$. It would have been even worth if compared to the experimental values at low temperature $(0 \mathrm{~K})$. On the contrary, the TB-SMA potential overestimates the mixing enthalpies in order to fit the critical temperatures. However, we notice on Table 4 that the overestimation by twice of the mixing enthalpies is not sufficient to get fully accurate critical temperatures. These temperatures are determined by canonical Monte Carlo simulations and are presented in the next section. If there is no analytical relation between the mixing enthalpies and the critical temperatures as in the TBIM model [73], there is a correlation between them. So we can't increase significantly the critical temperature without increasing also the mixing enthalpy. This is why we choose a compromise which is to get an overestimation by two of the mixing enthalpy and an underestimation also by two of the critical temperatures, while respecting the asymmetry between $\mathrm{Co}_{3} \mathrm{Pt}$ and $\mathrm{CoPt}_{3}$.

We finally compared the TB-SMA potential to the Tight Binding Ising Model that we have recently developed to study Co-Pt nanoalloys [30]. In that model, the effective pair interactions are evaluated in the diluted limit as the energy difference between two impurities separated by a given distance (first, second or third neighbors) and these two impurities at an infinite distance. We obtained values of $V^{1}, V^{2}$ or $V^{3}$ which are in good agreement with the TBIM values (see Table 5). Notably we find a positive value for $V^{3}$, which is necessary to stabilize the $L 1_{0}$ phase as compared to the $A_{2} B_{2}$, knowing the $V^{2}$ are positive according to DFT calculations [30,31]. The mixing enthalpies in each model are plotted in Fig. 1 where we see that the DFT calculations underestimate the experimental values whereas the TB-SMA and the TBIM models overestimate them.

\subsection{Monte Carlo simulations}

We performed Monte Carlo simulations in canonical $\left(\mathrm{N}_{C o}, \mathrm{~N}_{P t}, \mathrm{P}\right.$ and $\mathrm{T}$ constant) and semi-grand canonical ensembles $\left(\Delta \mu=\mu_{C o}-\mu_{P t}\right.$, $\mathrm{N}_{\text {tot }}=\mathrm{N}_{C o}+\mathrm{N}_{P t}, \mathrm{P}$ and $\mathrm{T}$ constant) where atomic displacements are proposed and accepted according to a Metropolis sampling [74] insuring to reach a Boltzmann distribution of the chemical configurations at equilibrium. In canonical ensemble, the concentration remains constant and the Monte Carlo trials consist to exchange the positions of two atoms of different nature. In the semi-grand canonical ensemble, the difference of the chemical potential of the two elements remains constant, which determines the average concentration at equilibrium and the Monte Carlo trials consist to permute the chemical nature of one

Table 5

Effective paire interations in both dilute limits calculated by TBIM [30], DFT and TB-SMA. In the TBIM model, the effective paire interactions do not depend on the concentration. In the DFT calculations, only the Pt dilute limit, $\mathrm{Co}(\mathrm{Pt})$, is reported since in the other limit, the two Co impurities interact with a strong magnetic coupling which makes confused the significance of the effective paire interaction in that case.

\begin{tabular}{lllll}
\hline (in meV) & $V^{1}$ & $V^{2}$ & $V^{3}$ & $V^{4}$ \\
\hline TBIM & 69 & 16 & 16 & - \\
DFT-GGA/PW91 Co(Pt) & 69 & 16 & - & - \\
TB-SMA Co(Pt) & 68 & 20.5 & 15 & 19 \\
TB-SMA Pt(Co) & 72 & 13.5 & 5 & 0 \\
\hline
\end{tabular}

atom. In each case we keep the same number of atoms in the simulation box.

For such simulations, we performed five to ten thousands macrosteps after leaving the system being equilibrated during two to five thousands macrosteps. Each macrostep consists of proposing randomly to any atom of the box, either a displacement or a chemical exchange (exchange or permutation), and a certain number of variations of the size of the box in case of bulk or surface simulations. In the bulk case, where periodic conditions apply on each direction, the lattice parameter of the alloy lattice increases from the one of the pure co to the one of the pure Pt. In the case of the surfaces, which are simulated by a slab with periodic conditions in two directions parallel to the surface, the core of the layer ( $60 \%$ of its thickness) is equilibrated according to the bulk alloy lattice parameter, fixing the lateral surface lattice parameter whereas the remaining planes at the vicinity of the surfaces can relax perpendicularly to the surface. If $M_{\text {steps }}$ is the number of macrosteps, $n_{d e p}$ and $n_{e x}$ the numbers of displacements and chemical exchanges per atom, and $n_{b o x}$ the number of trials for box size variations, the number of microsteps $N_{\text {steps }}$ is equal to:

$\mathrm{N}_{\text {steps }}=\mathrm{M}_{\text {steps }}\left(\mathrm{N}_{\text {atom }} \frac{\mathrm{n}_{\mathrm{dep}}+\mathrm{n}_{\mathrm{ex}}}{2}+\mathrm{n}_{\text {box }}\right)$

We take $\mathrm{n}_{d e p}=10, \mathrm{n}_{e x}=1$ and $\mathrm{n}_{b o x}=100$. For each statistical ensemble, we performed a series of simulations either with increasing (or decreasing) slowly the temperature in canonical ensemble or the chemical potential difference in semi-grand canonical ensemble, starting each time from the last configuration.

\section{Co-Pt bulk phase diagram}

\subsection{Order/disorder transition temperatures}

We characterize the bulk order/disorder transition temperatures using canonical ensemble. Heating/cooling Monte Carlo simulations start respectively with ordered/disordered phases. The chemical ordered phases are characterized by the occupancy of the four sublattices constituting the face centered cubic lattice mesh. On the Fig. 2, we see that starting with the $\mathrm{Co}_{3} \mathrm{Pt}$ ordered phase, the heating simulation

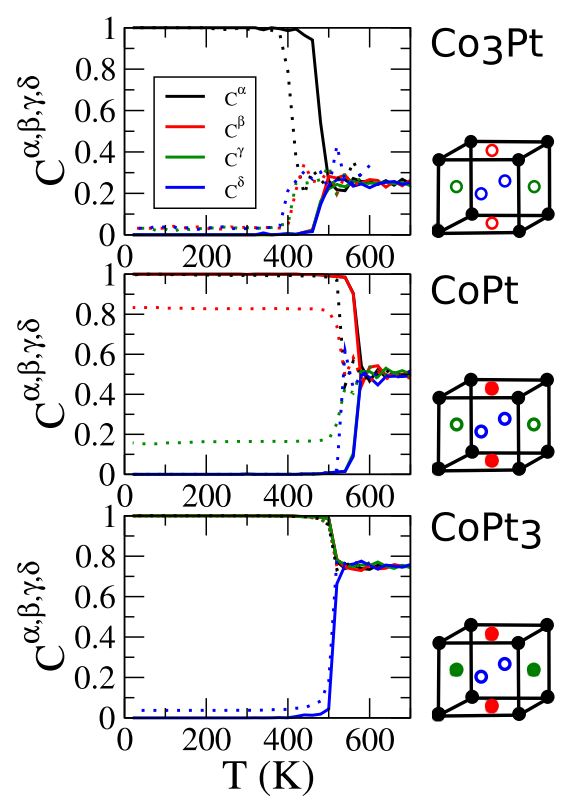

Fig. 2. Sublattice occupations as a function of the temperature showing the order/disorder transitions obtained from canonical Monte Carlo simulations for stoichiometric $\mathrm{Co}_{3} \mathrm{Pt}$, CoPt and $\mathrm{CoPt}_{3}$ alloys; heating curves (lines) and cooling curves (dotted lines). The four colors refer to the four sublattices in the fcc structure. 


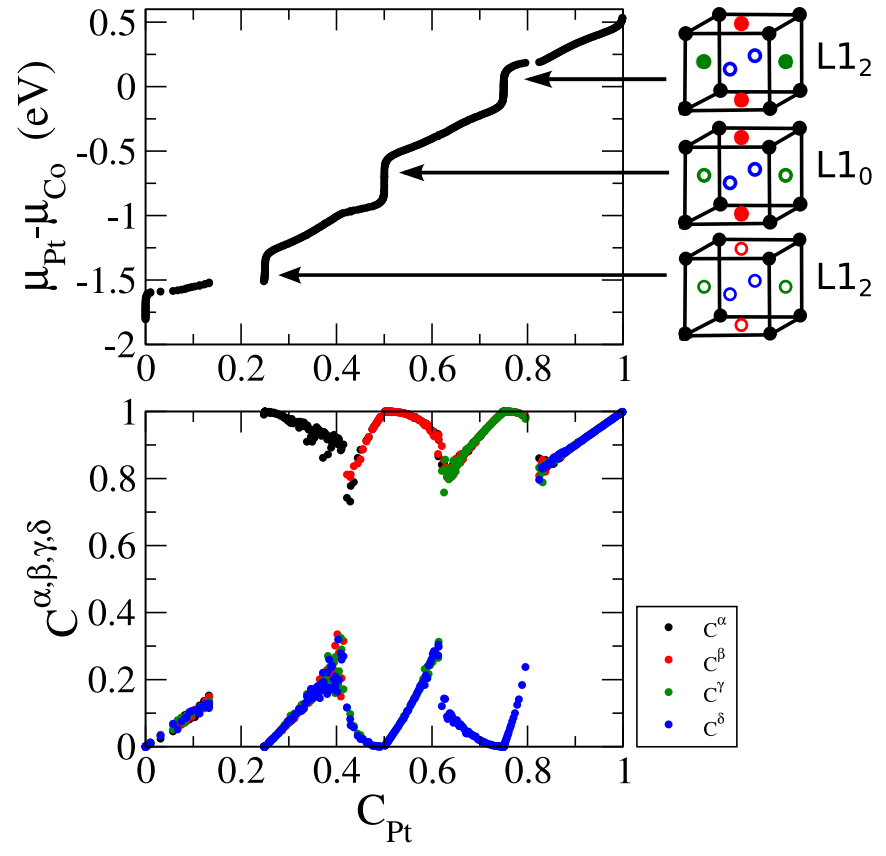

Fig. 3. Isotherm at $300 \mathrm{~K}$ of bulk $\mathrm{Co}_{1-c} \mathrm{Pt}_{c}$ alloys obtained by semi-grand canonical Monte Carlo simulations. In such simulations, the Pt concentration at equilibrium is obtained as a function of the chemical potential difference $\Delta \mu=\mu_{P t}-\mu_{C o}$. Here is plotted the chemical potential as a function of Pt concentration to illustrate the correspondence with the sublattice occupations in the graph below.

curves present one over four sublattice fully filled with Pt and the other three fully filled with Co atoms. This $\mathrm{Co}_{3} \mathrm{Pt} \mathrm{L}_{2}$ phase becomes fully disordered at $500 \mathrm{~K}$ (following the heating curve on Fig. 2). Looking at the cooling simulations, starting with the disordered phase at $25 \% \mathrm{of} P \mathrm{Pt}$ and high temperature, we get the ordering at $T=400 \mathrm{~K}$ with one sublattice fully occupied by Pt, the other three with Co. The order/disorder transition temperature of the $\mathrm{Co}_{3} \mathrm{Pt} \mathrm{L1} 1_{2}$ phase lies in between, around $450 \mathrm{~K}$, taking the average between heating and cooling transition temperatures. For $\mathrm{CoPt}$ as for $\mathrm{Co}_{3} \mathrm{Pt}$, we notice a slight hysteresis when heating and cooling which is not surprising as the order/disorder transition for infinite system is typically a first order transition. However, there is no hysteresis for the $\mathrm{CoPt}_{3}$, with the order/disorder transition being equal to $500 \mathrm{~K}$. Finally in the case of CoPt, the cooling simulation leads to partially occupied sublattices which comes from an anti-phase boundary with two disoriented $\mathrm{L}_{0}$ phases, which can happen in Monte Carlo simulations. The critical temperature of the CoPt phase is estimated to be around $540 \mathrm{~K}$. These temperatures are compared to the experimental ones in the Tab. 4 . We notice that the anisotropy between the $\mathrm{Co}_{3} \mathrm{Pt}$ and $\mathrm{CoPt}_{3}$ phases is respected even though all the temperatures are underestimated by $50 \%$ as compared to the experimental ones. There is really a weakness of the model to fit in the same time the mixing energies and the critical order/disorder temperatures that we have already noticed for example for the Pd-Au system [61]. The mixing enthalpy has to be overestimated in order to get reasonable critical temperatures as compared to experiment. The right critical temperature is achieved only in the TBIM model (see Fig. 1) for which the mixing enthalpy is the larger.

\subsection{Phase diagram}

The characterization of the Co-Pt bulk phase diagram is performed using semi-grand canonical isotherms simulations which means that we increase (inversely decrease) step by step $\Delta \mu$ starting from pure Co (inversely Pt) system and going to pure Pt (inversely Co) one. A typical example is illustrated on Fig. 3 where the sublattice occupations are

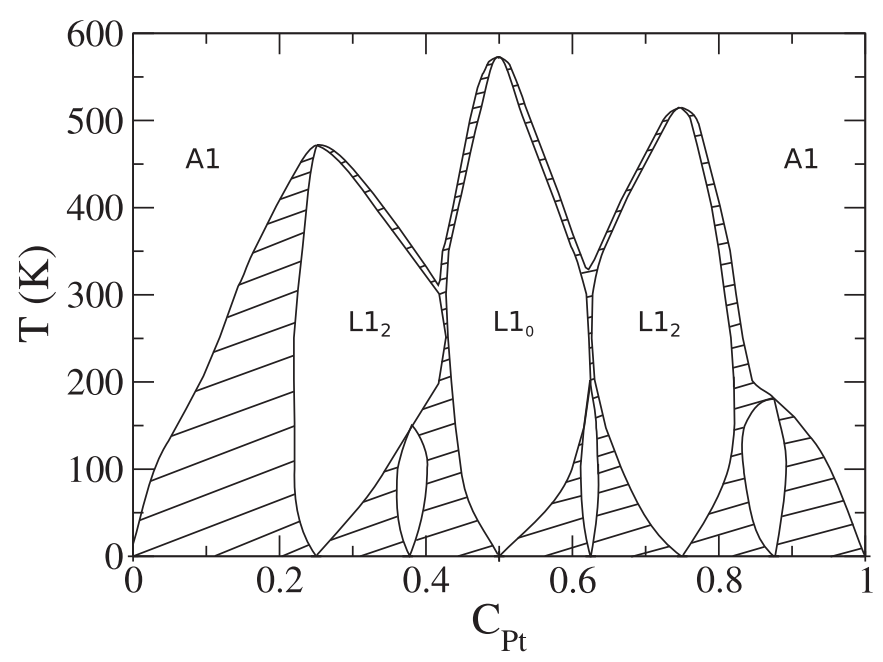

Fig. 4. Co-Pt bulk phase diagram. Beside the $\mathrm{L} 1_{2}, \mathrm{~L} 1_{0}$ and $\mathrm{L} 1_{2}$ phases referred in the graph, there are three other ordered phases at low temperature (below $200 \mathrm{~K}$ ) which are the $\mathrm{Co}_{5} \mathrm{Pt}_{3}$ at $\mathrm{c}=0.375$, the $\mathrm{Co}_{3} \mathrm{Pt}_{5}$ at $\mathrm{c}=0.625$ and the $\mathrm{CoPt}_{7}$ at $\mathrm{c}=0.875$.

plotted as a function of the concentration of Pt in the box. We notice that around the stoichiometric compositions corresponding to $\mathrm{Co}_{3} \mathrm{Pt}$, $\mathrm{CoPt}$ and $\mathrm{CoPt}_{3}$, the system is able to stabilize non-stoichiometric phases in a certain range of concentration. There are also concentration ranges notably around 0.20 and 0.8 where no phase is stabilized. This corresponds to phase-coexistence domains or biphasic domains. Indeed, the system does not find any equilibrium concentration corresponding to equilibrated phases in a given range of chemical potentials, except in the case where the simulation box displays itself two phases with an antiphase boundary inside the box, but this would represent an energy excess meaning that the Monte Carlo did not converge towards the minimum energy.

The complete bulk phase diagram is obtained from a series of isotherms at different temperatures, as shown in Fig. 4. The biphasic domains are depicted by hatched domains. We also observe new ordered phases at $\mathrm{c}=0.375\left(\mathrm{Co}_{5} \mathrm{Pt}_{3}\right), 0.625\left(\mathrm{Co}_{3} \mathrm{Pt}_{5}\right)$ and $0.875\left(\mathrm{CoPt}_{7}\right)$ which are the same as revealed by the TBIM study [30]. However the present phase diagram obtained within the new TB-SMA potential differs sensibly from the TBIM bulk phase diagram (cf. Fig. 6 of [30]) at least by three important points. The first one is the critical order/disorder transition temperatures which are underestimated by the TB-SMA potential as compared to the TBIM where they have been properly fitted. The second point is the asymmetry of the TB-SMA bulk phase diagram which is more similar with the experimental one. Third, the $\mathrm{Co}_{7} \mathrm{Pt}$ is not stabilized by the TB-SMA potential at very low temperature (less than $300 \mathrm{~K}$ ) as compared to the TBIM, noting that none of these additional low temperature ordered phases at $\mathrm{c}=1 / 8,3 / 8,5 / 8$ and $7 / 8$ have been observed experimentally.

\section{Co-Pt alloys surfaces}

One particularity of the Co-Pt system, as the Ni-Pt one [37,43], is to present a surface segregation reversal between the dense (111), (100) alloys surfaces and the more open (110) one. Indeed, it has been observed experimentally by Low Energy Electron Diffraction (LEED) that on (111) $\mathrm{Co}_{3} \mathrm{Pt}$ and $\mathrm{CoPt}_{3}$ alloys surfaces $[38,39]$, and on $(100) \mathrm{Co}_{3} \mathrm{Pt}$ and $\mathrm{CoPt}_{3}$ ones [40-42], the surface is enriched in Pt whereas on the (110) $\mathrm{Co}_{3} \mathrm{Pt}$ one $[44,45]$ the top surface is almost pure in Co followed by a Pt enrichment in the subsurface layer and again a Co enrichment in the third layer. This structure has been called the sandwich structure with a stacking of almost pure monoatomic layers Co/Pt/Co $[43,44]$. This face-related segregation reversal when going from the (111) to the (110) face has been reproduced theoretically by different energetic 


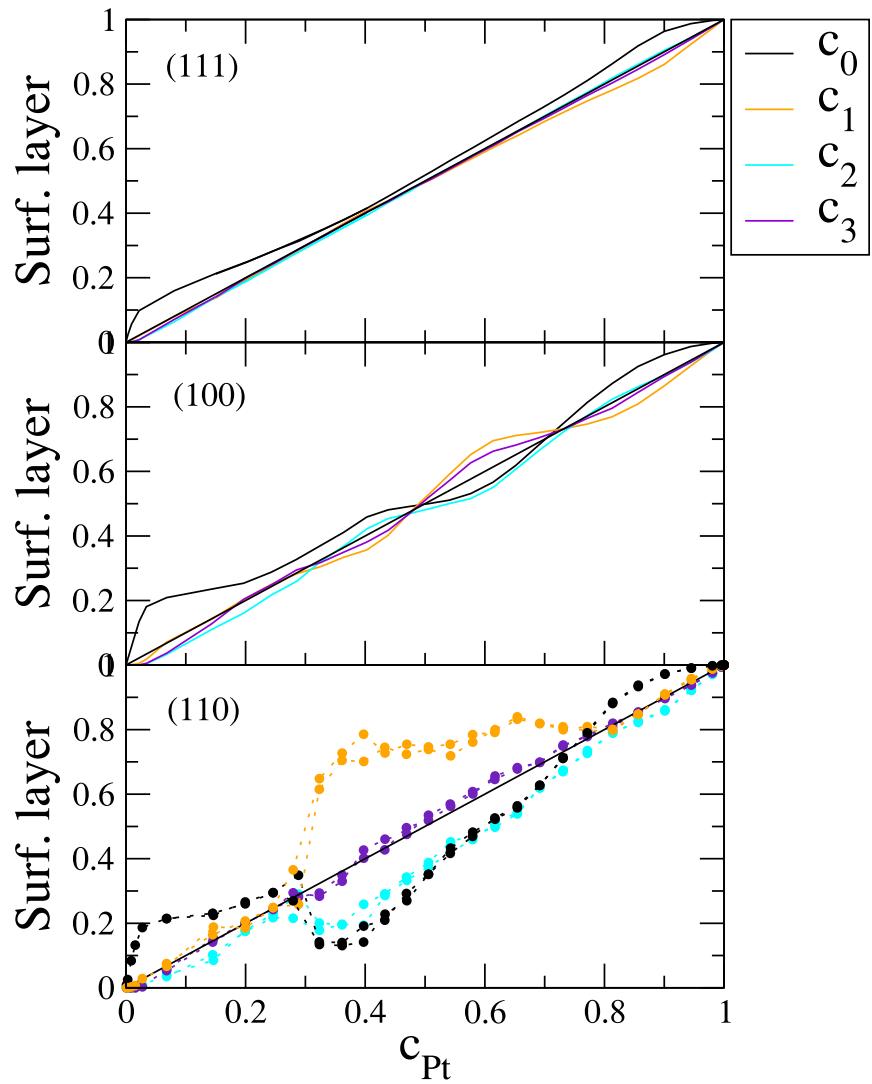

Fig. 5. Segregation isotherms at $650 \mathrm{~K}$ for the (111), (100) and (110) surfaces. The first diagonal corresponds to no segregation. The four curves with different colors represent the concentration of different atomic layers: the surface layer, $c_{0}$ (in black), the subsurface layer, $c_{1}$ (in orange), and so on for $c_{2}$ (in cyan) and $c_{3}$ (in violet). The Monte Carlo simulations for the (110) surface are less regular than for the more compact surfaces so we used dotted line showing the results are more dispersed. (For interpretation of the references to colour in this figure legend, the reader is referred to the web version of this article.)

models going from the empirical embedded atom method (EAM) [75], to a density functional theory calculation coupled with the coherent potential approximation (CPA) [76], through the semi-empirical TightBinding Ising model (TBIM) [77] in the case of the Pt-Ni system, but essentially in a mean-field approximation. Here we use a TB-SMA semiempirical potential fitted to DFT calculations and Monte Carlo simulations giving both long-range and short-range ordering.

\section{1. (111), (100) and (110) Co-Pt surface at high temperature}

We recall that the parameters of the TB-SMA energetic model have been fitted to reproduce the surface segregation reversal for the Co-Pt system. In Fig. 5, we plot the concentration of the top surface layer $\left(\mathrm{c}_{0}\right)$ and three layers below $\left(c_{1}, c_{2}\right.$ and $\left.c_{3}\right)$ as a function of the Pt concentration in the slab for the disordered alloy (high temperature phase). The slabs for the different surfaces consist of twenty atomic planes and around forty atoms per plane. In order to get the segregation reversal, we constrain surface energies of the pure metals to be almost identical (at least in eV/at., see Table 1) on each surface orientation. Therefore, the difference in lattice parameter (size effect) and the alloy effect are the main driving forces for surface segregation. This leads to a weak $\mathrm{Pt}$ surface segregation on the (111) and (100) alloys surfaces, stronger in the dilute limit because the two driving forces are more important, and a clear Co surface segregation on the (110) surface in the range of composition between $30 \%$ and $75 \%$ of Pt. The segregation is accompanied by an oscillation profile well established in the (110) surface in the composition range $30-75 \%$ of $\mathrm{Pt}$ which is in good agreement with
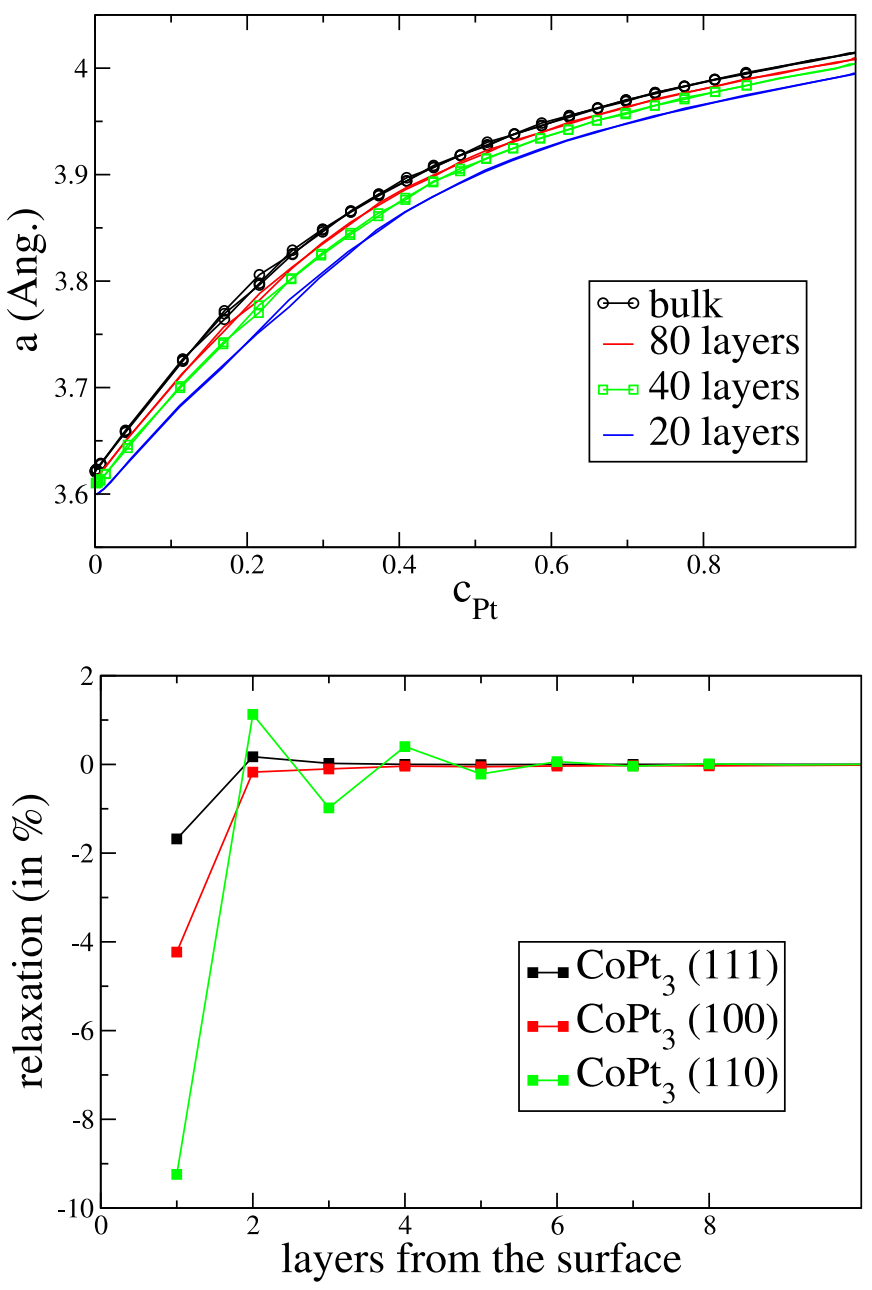

Fig. 6. Top: lattice parameter in the bulk and (100) surface slabs of 80,40 and 20 atomic layers in the $\mathrm{x}, \mathrm{y}, \mathrm{z}$ directions for the $\mathrm{CoPt}_{3}$ alloy. The $\mathrm{z}$ directions for the surface slabs are determined in the middle of the slab to be compared to the bulk. The $\mathrm{x}$ and $\mathrm{y}$ are averaged on the whole slab. Bottom: vertical relaxation profile in the $\mathrm{CoPt}_{3}$ alloy surfaces at $300 \mathrm{~K}$.

the sandwich profile obtained in the experiments.

The volume of the slab is optimized during the Monte Carlo simulation in order to keep the constant pressure equal to zero. As the slab has to reproduce a surface i.e. a semi-infinite crystal we need to optimize its thickness in order to get the same lattice constant in the middle of the slab as in the bulk. This is what is illustrated in the Fig. 6 for the (100) surface of the $\mathrm{CoPt}_{3}$ alloy at $800 \mathrm{~K}$. Depending on the thickness of the slab (going from 20, 40 to 80 layers), we see that the lattice mesh in the slab converges towards the one of the bulk. We considered that the 20 layers slab (for the (100) slab) is sufficient to give the correct lattice parameter and surface stress at the surface. We get the same results if we fix the lateral dimension of the slab to the one of the bulk alloy with same composition and same temperature. Apart from the core of the slab, the surface undergoes an atomic contraction illustrated at the bottom of Fig. 6 with the relaxation profile of the $\mathrm{CoPt}_{3}$ alloy (111), (100) and (110) surfaces at $300 \mathrm{~K}$.

\section{2. (111) Co-Pt surface at $300 \mathrm{~K}$}

The (111) surface is simulated by a slab of twenty atomic planes with thirty six atoms (six by six) per atomic layer as illustrated on the Fig. 7, where the snapshots represent the top layer. The slab is divided in three regions in its thickness: the core comprises twelve layers centered in the middle of the slab whereas each surfaces on top and bottom 

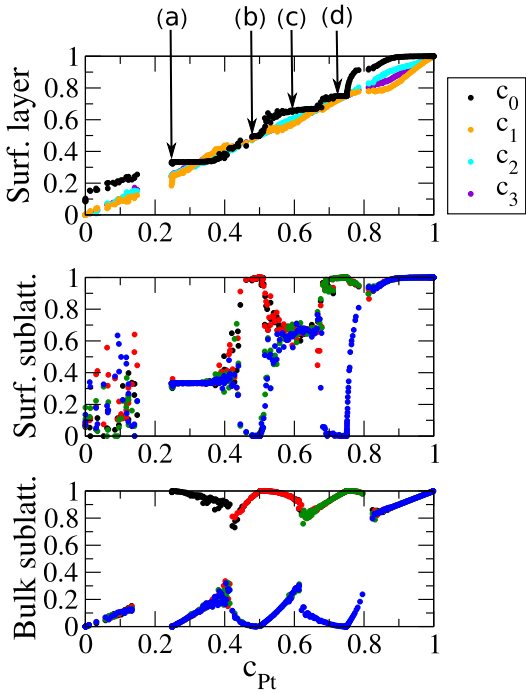

(a)

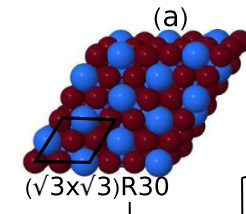

$(\sqrt{3} \times \sqrt{3}) \mathrm{R} 30$

(c)
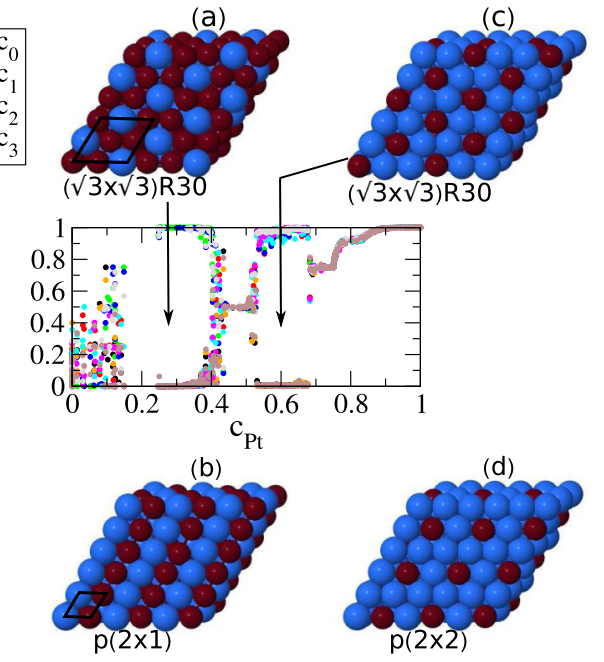

Fig. 7. Segregation isotherms at $300 \mathrm{~K}$ for the (111) surface. The first graph represents the surface layers $\mathrm{Pt}$ concentrations with $c_{0}$ (in black) for the top surface layer, $c_{1}$ (orange) for the subsurface layer, $c_{2}$ (cyan) for the third layer and $c_{3}$ (violet) for the fourth one. In the middle row are plotted the surface sublattices with $2 \times 2$ i.e. 4 sublattices (graph on the left) and $3 \times 3$ i.e. 9 surface sublattices (graph on the right). Bottom graph recalls the bulk sublattices as in Fig. 3. All these graphs are reported as a function of $\mathrm{c}_{P t}$ which represents the bulk Pt concentration equivalent to the one in the core of the slab. Finally, some snapshots of the top of the slab illustrate some peculiar surface structures (a), (b), (c) and (d). Pt atoms are in blue and Co ones in red. (For interpretation of the references to colour in this figure legend, the reader is referred to the web version of this article.)

comprises four layers each. The central region of the slab has the same properties as the bulk. In particular, the lattice parameter is the one of the bulk of the same composition (obtained by the variation of the size of the box in the Monte Carlo simulations). We checked also that we recover the same ordered phases as in the bulk calculations. In the following and for all the surfaces, the "bulk" Pt concentration $c_{P t}$ refers to the Pt concentration in the core of the slab (i.e. in the corresponding bulk concentration of a semi-infinite system). In Fig. 7, the top layer concentration $c_{0}$ presents different plateaus (a), (b), (c) and (d) which characterize different surface ordered superstructures depending on the bulk Pt concentration. Below 15\% of Pt, the bulk alloy is disordered and there is a slight Pt surface segregation illustrated by $c_{0}$ slightly higher than the other layer concentrations which follow the first diagonal. From $25 \%$ of Pt, the first plateau (a) corresponds to a Pt surface segregation of $33 \%$ for the $\mathrm{Co}_{3} \mathrm{Pt}$ alloys with the $\mathrm{L}_{2}$ phase. This result is consistent although not fully in agreement with an experimental observation on the $\mathrm{Pt}_{25} \mathrm{Co}_{75}(111)$ alloy surface [38] where the Pt enrichment is estimated to be around $50 \%$ but on a disordered alloy. The experiments measure also a depletion of $\mathrm{Pt}$ in the second layer and a slight enrichment of the third layer, the rest of the layers being homogeneous. This is in qualitative agreement with our model although the oscillations of composition in our model are weaker. However, the experiments performed on the disordered alloy do not observe any long-range ordering at the surface, but a short-range ordering locally arranged with a $(1 \times 2)$ unit cell. Here we obtain the $(\sqrt{3} \times \sqrt{3})$ R30 bidimensional ordering characterized by nine different surface sublattices plotted in Fig. 7 where three of them are filled with Pt and the other six, with Co. The $(\sqrt{3} \times \sqrt{3})$ R30 superstructure is not a prolongation of the $\mathrm{L} 1_{2}$ bulk ordered phase but it takes place all over the $\mathrm{L}_{2}$ bulk phase domain, as can be seen with the correspondence of the surface sublattices and the bulk sublattices (on Fig. 7).

To illustrate the correspondence between the surface superstructures and the bulk phases, we show on a scheme (Fig. 11) the succession of the 2D surface phases in parallel with the 3D bulk phases as a function of the Pt bulk concentration. At the beginning of the $\mathrm{L} 1_{0}$ bulk phase domain (at about $40 \%$ of $\mathrm{Pt}$ ), the $\mathrm{p}(2 \times 1)$ surface structure takes place, which is characterized by two surface sublattices occupied by Pt and the other two by Co (on Fig. 7), but $\mathrm{c}_{0}$ still increases up to $\mathrm{c}_{0}=0.5$ reaching a small plateau in (b) for the stoechiometric $\mathrm{L} 1_{0}$ phase. At the equiconcentration, the $\mathrm{p}(2 \times 1)$ superstructure is basically the
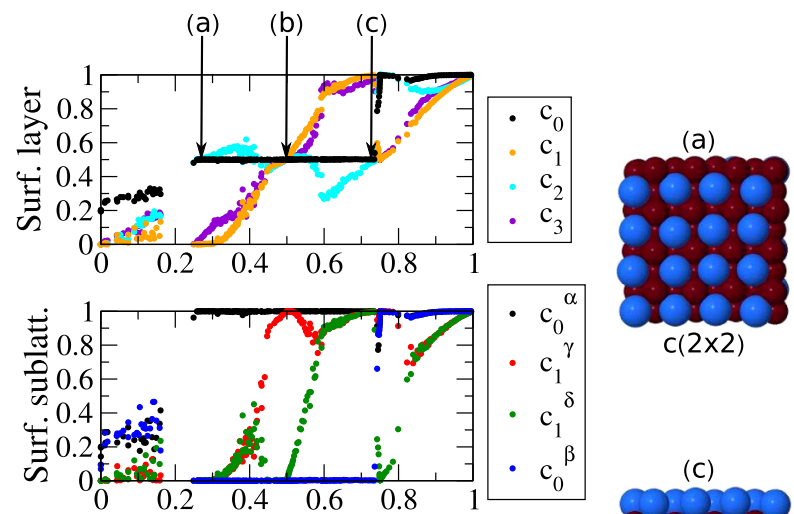

(b)

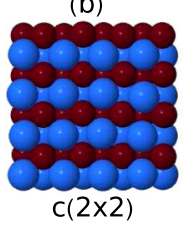

(c)
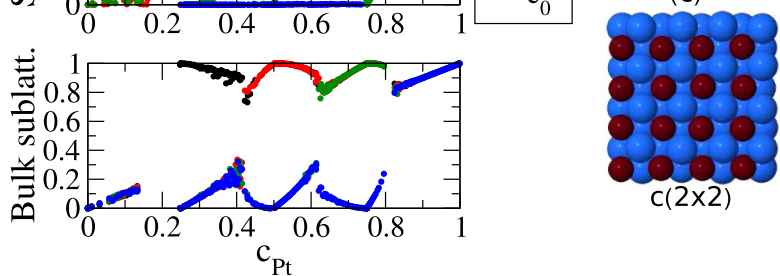

Fig. 8. Segregation isotherms at $300 \mathrm{~K}$ for the (100) surfaces. Same graphs as Fig. 7 except there are only two surface sublattices ( $\mathrm{c}_{0}^{\alpha}$ and $\mathrm{c}_{0}^{\beta}$ ) so we plotted also the two equivalent sublattices of the subsurface layer $\left(\mathrm{c}_{1}^{\gamma}\right.$ and $\left.\mathrm{c}_{1}^{\delta}\right)$ to recall the ones of the bulk. 


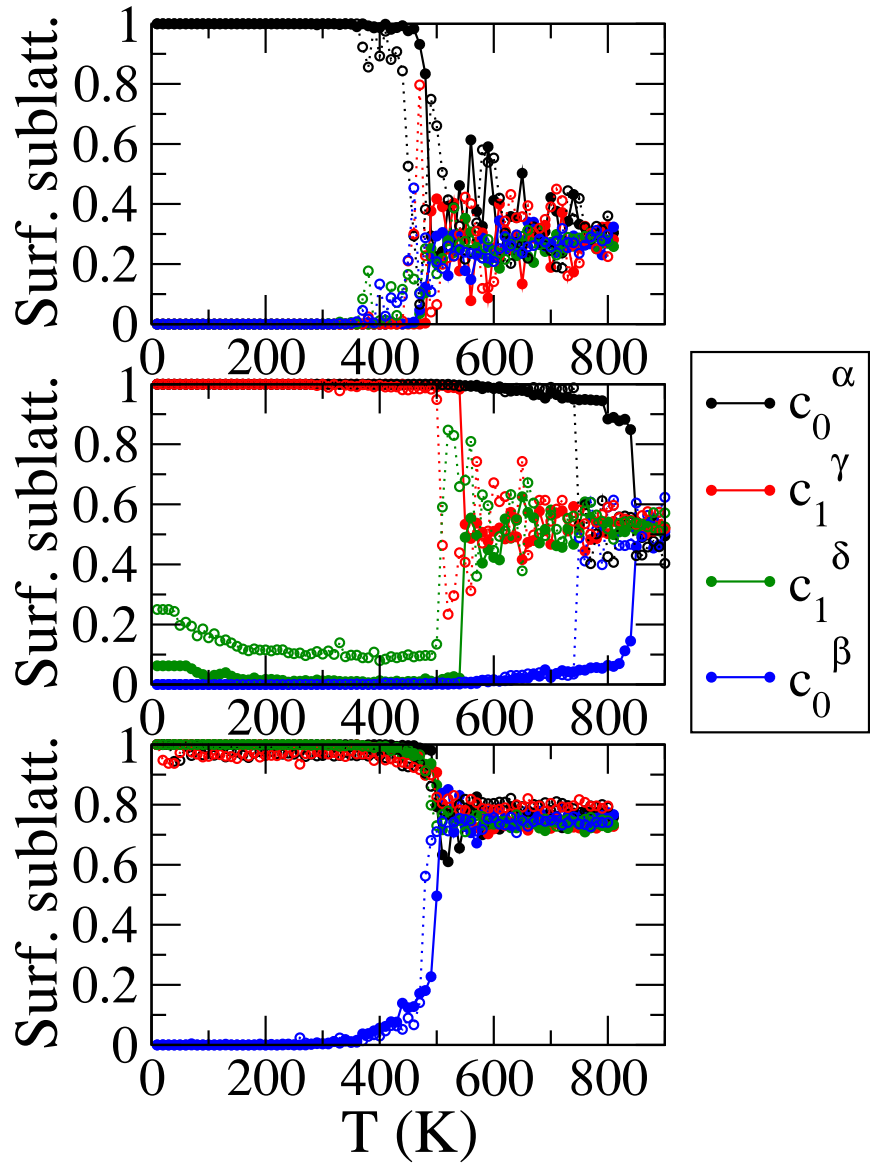

Fig. 9. Sublattices of the (100) surface as a function of the temperature in canonical Monte Carlo simulations for the three ordered phases: $\mathrm{Co}_{3} \mathrm{Pt}$, $\mathrm{CoPt}$ and $\mathrm{CoPt}_{3}$ from top to bottom, full line for heating and dotted line for cooling.

cut of the $\mathrm{L} 1_{0}$ bulk phase along a (111) plane. We also notice that the concentration of each layer near the surface $\left(c_{0}, c_{1}, c_{2}\right.$ and $\left.c_{3}\right)$ are precisely equal to 0.5 . By increasing the Pt concentration, in the over stoechiometric part of the $\mathrm{L}_{0}$ phase, $\mathrm{c}_{0}$ increases up to a large plateau for $\mathrm{c}_{0}=0.66$ (c) corresponding to the Pt-rich $(\sqrt{3} \times \sqrt{3})$ R30 2D phase. Such superstructure is stabilized allover two bulk phases: the over stoechiometric $\mathrm{L} 1_{0}$ phase and the under stoechiometric $\mathrm{L} 1_{2}$ one. Around $66 \%$ of Pt in the bulk, the surface concentration increases up to an other step for $c_{0}=0.75$, the last remarquable plateau (d), where all the surface layers concentration are equal to 0.75 and the surface sublattices are characteristic of the Pt-rich $\mathrm{p}(2 \times 2)(\mathrm{d})$. This surface ordering is the perfect termination of the $\mathrm{L}_{2}$ stoechiometric bulk phase along the (111) orientation.

Finally, just above $75 \%$ of Pt, there is a noticeable Pt enrichment corresponding to the over stoechiometric $\mathrm{CoPt}_{3}$ phase and forming an almost pure Pt surface layer after $80 \%$ of $\mathrm{Pt}$ in the disordered alloy. This last result is in good agreement with LEED measurements [39] except that once more the oscillating profile measured experimentally is more accentuated than in the model. Indeed the experiment gives a subsurface depletion of $50 \%$ of Pt whereas we get only a very slight effect within the model. The surface and the bulk below are chemically disordered according to the solid solution in the bulk phase diagram.

Now, if we compare the present model with a more simple on-lattice Ising model [30], we notice two main differences. With the symmetric Ising model we get essentially two types of superstructure: the $p$ $(2 \times 2)$ for $\mathrm{Co}_{3} \mathrm{Pt}$ and $\mathrm{CoPt}_{3}$ alloys and the $\mathrm{p}(2 \times 1)$ for the CoPt alloy. Within the TB-SMA, the $(\sqrt{3} \times \sqrt{3})$ R30 type of superstructure appears on both sides, which could be the result of a coupling between chemical ordering and atomic relaxations. Such structure has already been reported in a theoretical study on the Pd-Au system [61], with an interatomic potential allowing atomic relaxations. The second difference is that the Pt surface segregation was rather amplified with the Ising model. But in both models, the oscillating profiles are less pronounced than what is observed experimentally.

The $(\sqrt{3} \times \sqrt{3})$ R30 surface structure is a 2D chemical ordering which has no relation with the underlying bulk alloy and has been seen by atom deposition in ultra-vacuum conditions on pure metal surfaces in systems like $\mathrm{Sn}$ on $\mathrm{Pt}(111)$ [50,51,78-80], $\mathrm{Sb}$ on $\mathrm{Cu}(111)$ and $\mathrm{Ag}$ (111) [81], Bi on $\mathrm{Cu}(111)$ [54,55] or $\mathrm{Ag}(111)$ [56], $\mathrm{Te}$ on $\mathrm{Cu}(111)$ [53], $\mathrm{Sn}$ on $\mathrm{Ni}(111)$ [52], and $\mathrm{Pb}$ on $\mathrm{Ni}(111)$ [57] or $\mathrm{Ag}(111)$ [58-60]. It has also been obtained from surface segregation of solid solutions of $\mathrm{Sn}$ or $\mathrm{Al}$ in copper-based alloys single crystal surfaces: $\alpha-\mathrm{Cu}_{.95} \mathrm{Sn}_{.05}(111)$ [47] and $\alpha-\mathrm{Cu}_{.84} \mathrm{Al}_{.16}(111)[48,49]$. The characteristics of the $(\sqrt{3} \times \sqrt{3}) \mathrm{R} 30$ surface ordering is that it has no connection with long-range order in the bulk. The substitutional alloys are stable against the adsorbed systems as soon as the segregated atoms are in minority. These systems are mainly composed of one transition metal and one semiconducting or bad-conducting elements: $\mathrm{Sn}, \mathrm{Sb}, \mathrm{Te}, \mathrm{Pb}, \mathrm{Bi}$ or $\mathrm{Al}$, forming either
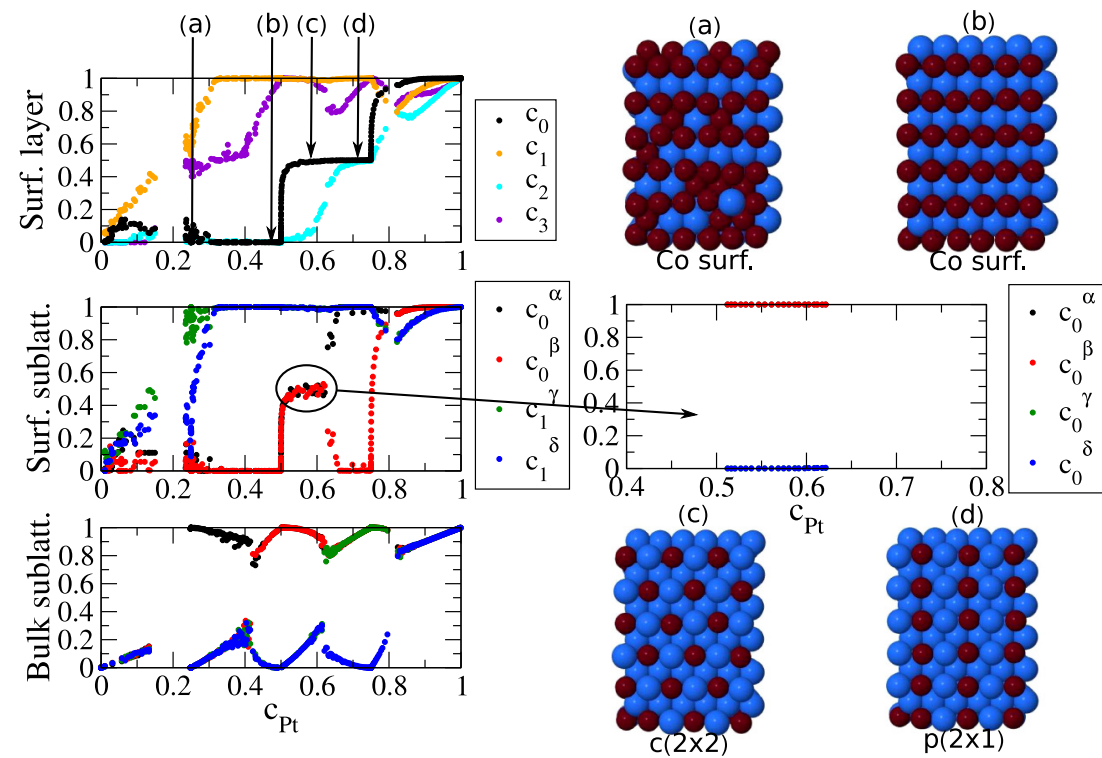

Fig. 10. Segregation isotherms at $300 \mathrm{~K}$ for the (110) surfaces. Same as Figs. 7 and 8. 


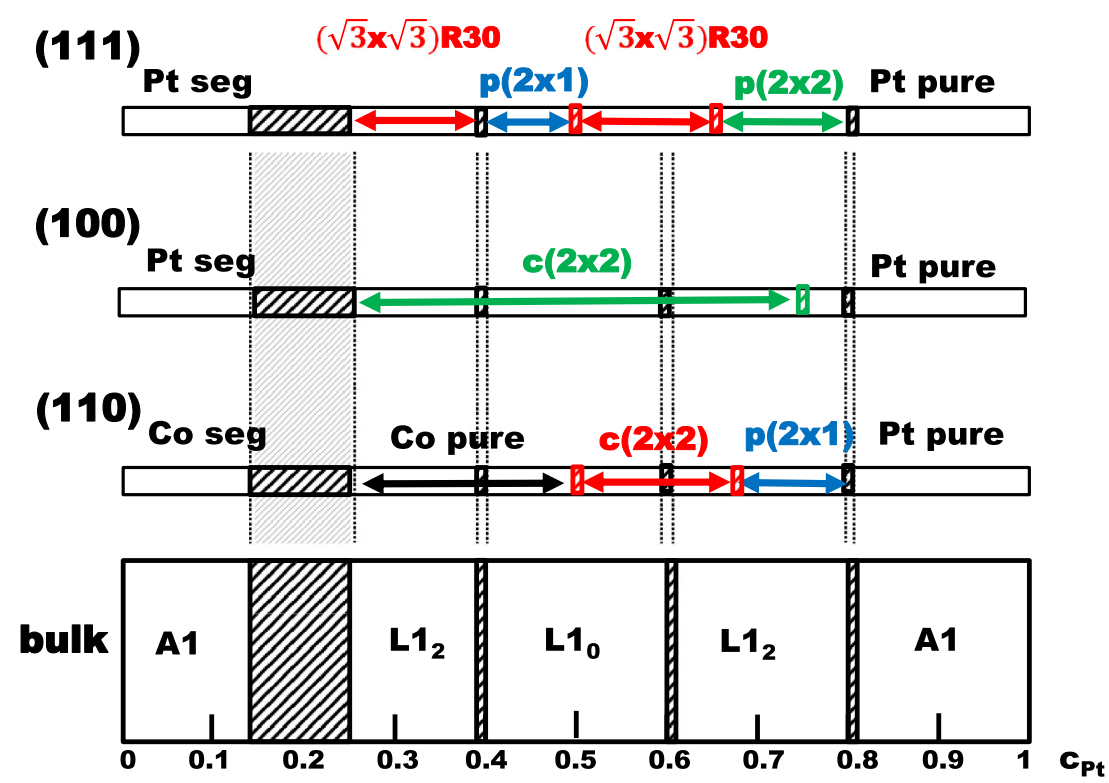

Fig. 11. Schematic representation of the surface structures on the (111), (100) and (110) orientations detailed in the Figs. 7-10.

intermetallic compounds with strong ordering tendency leading to well defined ordered compounds as the well known Cu-Al system but not necessarily since there are also immiscible systems mainly with $\mathrm{Pb}$ and $\mathrm{Bi}$. To our knowledge, there is no reported experimental observation of the $(\sqrt{3} \times \sqrt{3})$ R30 surface ordering on purely metallic alloys. And yet, this structure is theoretically predicted using mean-field Bragg-Williams approximations in systems with an ordering tendency (first neighbors interactions) and surface segregation of one element (the bigger one) $[51,80,82]$.

\section{3. (100) Co-Pt surface at $300 \mathrm{~K}$}

The dimensions of the slab are a three by three lattice mesh which means thirty two atoms per atomic plane and twenty one atomic planes. The surface concentration $c_{0}$, plotted in the first graph of the Fig. 8, presents two plateaus and starts with a Pt surface segregation in the Corich domain. The surface is enriched in Pt as compared to the Pt concentration in the bulk (core of the slab). We notice a slight oscillating profile which concerns essentially the top surface and subsurface layers. The layers below are homogeneous and equal to the bulk sublattices concentrations, up to a global composition of $15 \%$ after which the surface displays a miscibility gap as in the bulk between $15 \%$ and $25 \%$ of Pt.

At the right limit of the miscibility gap, corresponding to $25 \%$ of $\mathrm{Pt}$ (a), the bulk is ordered according to the $\mathrm{L}_{2}$ stoechiometric $\mathrm{Co}_{3} \mathrm{Pt}$ phase, and the surface layers concentrations oscillate between 0.5 and 0 extending the $\mathrm{L} 1_{2}$ phase up to the surface. The surface structure in (a) is the $c(2 \times 2)$ which is well characterized by the surface sublattices $\left(c_{0}^{\alpha}=1\right.$ and $\left.c_{0}^{\beta}=0\right)$. Increasing $c_{P t}$ from 0.25 to 0.40 , the surface concentration remains constant equal to 0.5 with the $c(2 \times 2)$ while $c_{1}$ follows the stoichiometric deviation of the $\mathrm{L} 1_{2}$ phase. The comparison with the experimental results performed by quantitative LEED analysis [40] is good for the four surface layers although the experiments are performed on a disordered $\mathrm{Co}_{3} \mathrm{Pt}(100)$ alloy. The surface reconstruction observed by LEED and chemically resolved STM is complex with $\mathrm{c}(2 \times 2)$ domains limited by shifted rows producing the $(1 \times 5),(1 \times 6)$ and $(1 \times 7)$ periodicity. The model reproduces only the $c(2 \times 2)$ superstructure without the right simulation conditions to get longer range periodicities (the slab dimensions should be extended beyond the three by three lattice mesh). A deeper investigation should be performed to look for the shifted-row reconstruction observed experimentally, but this question is beyond the scope of the present study.
At $40 \%$ of $\mathrm{Pt}$ and beyond, the $\mathrm{c}(2 \times 2)$ superstructure in (b) remains the same but the bulk phase underneath changes to the $\mathrm{L} 1_{0}$ which is naturally stoechiometric at $50 \%$ in which case the surface is made of the mixed variant of the $\mathrm{L} 1_{0}$ phase. Around $50 \%$ of $\mathrm{Pd}$, in the out of stoechiometric $\mathrm{L} 1_{0}$ stability domain, $\mathrm{c}_{1}, \mathrm{c}_{2}$ and $\mathrm{c}_{3}$ accommodates the stoechiometry variations except $c_{0}$ which remains the same with the $c(2 \times 2)$ structure at the surface. The same behavior arises with increasing the composition from CoPt to the slightly under stoichiometric $\mathrm{CoPt}_{3}$ phase: the surface remains the same whereas the subsurface layer follows the sublattice occupation of the Pt-rich $\mathrm{L}_{2}$ bulk ordered phase. All over this plateau of the $c_{0}$ curve, we can notice that the surface remains perfectly ordered with the $c(2 \times 2)$ superstructure whereas the layers below follow the bulk ordered phases with out of stoichiometry phases. The coexistence domains are so narrow in that side of the bulk phase diagram that we can not distinguish it on the alloy surface. The $c(2 \times 2)$ superstructure as shown in the Fig. 8 coexists with the three kinds of bulk ordered phases: the $\mathrm{L} 1_{2}$ Co-rich in the over stoichiometric part, the whole $\mathrm{L} 1_{0}$ domain and the $\mathrm{L} 1_{2} \mathrm{Pt}$-rich, in the under stoichiometric part. Such result is illustrated on the Fig. 11.

At the stoichiometric $\mathrm{CoPt}_{3}$ composition, the surface concentration switches from 0.5 to 1 whereas in the same time the subsurface falls to 0.5 , the rest of the slab remaining with the $\mathrm{L}_{2}$ ordered phase all over the over stoichiometric part, only the termination of the surface changed from the mixed to the pure layer in the alternation of mixed/ pure planes of the $\mathrm{L} 1_{2}$ Pt-rich phase. This ordered phase is stable up to about $83 \%$ of $\mathrm{Pt}$, then all the layers below the surface become homogeneous to form the disordered bulk phase with Pt surface segregation. In that composition range, the layers beyond the surface are homogeneous and their concentration is equal to the bulk one in the disordered phase. The Pt segregation on the first surface layer of an alloy with $80 \%$ of Pt has been observed by Low Energy Ion Scattering Spectroscopy (LEISS) and X-ray Photoelectron Spectroscopy (XPS) $[41,42]$. The experiments show that the subsurface is enriched in Co following an oscillating profile. The comparison is not direct with our simulations because their sample was disordered (annealed at $900 \mathrm{~K}$ ) whereas in the present case, at $300 \mathrm{~K}$, the bulk is ordered with the $\mathrm{L}_{2}$ structure up to the alloy composition of $80 \%$ of Pt. However, just above $80 \%$, the bulk becomes disordered and the subsurface composition is depleted in $\mathrm{Pt}$ as compared to the bulk composition (60\% of Pt instead of $80 \%$ ) just in agreement with the experimental results.

If we compare these results with the TBIM study on rigid 
lattice [30], the main difference arises at the equiconcentration alloy where the TBIM model preferred the pure variant (alternation of pure layers along the (100) direction), whereas the TB-SMA interatomic potential displays the mixed variant. The shift from mixed to pure surface happens at $75 \%$ of $\mathrm{Pt}$, in coexistence with the $\mathrm{L} 1_{2}$ over stoichiometric $\mathrm{CoPt}_{3}$ phase up to $83 \%$ of $\mathrm{Pt}$ and then in coexistence with the solid solution.

Finally, we have simulated the evolution of the different surface ordered phases (a), (b) and (c) of Fig. 8 as a function of the temperature in a canonical ensemble at constant concentration. The results are shown on Fig. 9 where we see the $\mathrm{c}(2 \times 2)$ superstructure on the $\mathrm{L}_{2}$ phases, either Co-rich or Pt-rich, gets disordered at the same temperature as in the bulk alloy (see Fig. 2) i.e. around $500 \mathrm{~K}$. This result is in agreement with other theoretical studies using mean-field Brag$\mathrm{g}$-Williams theory $[83,84]$. However, we find that the $\mathrm{c}(2 \times 2)$ on top of the $\mathrm{L} 1_{0}$ phase remains ordered until $800 \mathrm{~K}$ which means at a temperature $200 \mathrm{~K}$ higher than the bulk critical order/disorder temperature. This is a quite interesting result which should have important implications in the nanoalloys ordering at the equiconcentration, even if it has been shown experimentally that the order/disorder temperature of small nanoalloys of CoPt are well lowered [20] as compared to the bulk one.

\section{4. (110) Co-Pt surface at $300 \mathrm{~K}$}

The (110) surface is simulated by a slab of forty one atomic planes with 36 atoms ( 6 by 6 ) per atomic layer as illustrated on the Fig. 10.

The surface segregation reversal between the dense (111) and (100) faces, and the more opened (110) one is clearly evidenced at low temperature up to $50 \%$ of Pt. The main experimental results showing such reversal concerns the $\mathrm{Co}_{3} \mathrm{Pt}(110)$ surface alloy [44] or more precisely the $\mathrm{Co}_{65} \mathrm{Pt}_{35}(110)$ alloy [45] where the LEED analysis leads to a sandwich-like profile with a Co-pure surface followed by an almost Ptpure subsurface and still after a Co-pure third layer. The composition of $35 \%$ corresponds to the maximum of Co segregation in the present model at $650 \mathrm{~K}$ i.e. in the disordered state (see Fig. 5). At low temperature $(300 \mathrm{~K})$, the model predicts a sandwich profile in the concentration range between $30 \%$ to $50 \%$ of Pt as can be seen on the Fig. 10, which coexists with both the $\mathrm{L}_{2}$ Co-rich phase from $30 \%$ to $40 \%$ of Pt and with the $\mathrm{L}_{0}$ phase from $40 \%$ to $50 \%$ of Pt. In this last case, the sandwich at the surface is nothing else that the prolongation of the bulk ordered phases up to the surface (Fig. 10-(b)).

Looking at the curves in more details, we observe that between $25 \%$ and $30 \%$ of $\mathrm{Pt}$ in the bulk, the concentration of the subsurface $\left(\mathrm{c}_{1}\right)$ increases from 0.5 to 1 , whereas $c_{0}$ and $c_{2}$ remain at 0 and $c_{3}$ makes a plateau at 0.5 (see Fig. 10 and structure (a)). This alternation of pure and mixed layer near the surface propagates in the slab, which characterizes well the $\mathrm{Co}_{3} \mathrm{Pt} \mathrm{L}_{2}$ phase in the bulk up to $40 \%$ of Pt. Between $30 \%$ and $40 \%$ of $\mathrm{Pt}$, we get the sandwich structure in the first three layers, the next layer with concentration $c_{3}$ increasing from 0.5 to 1 , together with the appearance of the $\mathrm{L} 1_{0}$ phase in the bulk ( $c_{3}$ seems to vary according to the off stoichiometry of the $\mathrm{L} 1_{0}$ phase) up to the perfect sandwich structure prolongated in the bulk via the stoechiometric $\mathrm{L} 1_{0}$ phase at $50 \%$ (Fig. 10-(b)).

Beyond $50 \%$ of $\mathrm{Pt}, \mathrm{c}_{0}$ changes abruptly from 0 to 0.5 reaching an other large plateau consisting of a mixed surface. Looking at the surface sublattices in the middle graphs of the Fig. 10, there are two different surface structures with the same composition. The first one, from 50 to $65 \%$ of Pt in bulk, is characterized by four surface sublattices occupied two by two and corresponding to a $\mathrm{c}(2 \times 2)$ superstructure (Fig. 10(c)). This superstructure takes place on top of the $\mathrm{L} 1_{0}$ ordered phase, but without stacking relation with the bulk ordered planes. The second one, from 65 to $75 \%$ of Pt, is characterized by a $\mathrm{p}(2 \times 1)$ (Fig. 10-(d)) which is the continuity of the $\mathrm{L} 1_{2}$ phase below and characterized by two surface sublattices: $c_{0}^{\alpha}=1$ and $c_{0}^{\beta}=0$. The surface structure transition from the $\mathrm{c}(2 \times 2)$ to the $\mathrm{p}(2 \times 1)$ is therefore correlated with the bulk phase transition from $\mathrm{L}_{0} \mathrm{CoPt}$ to $\mathrm{L}_{2} \mathrm{CoPt}_{3}$.

Finally, at the end of the plateau, there is a continuous transition between the $\mathrm{p}(2 \times 1)$ surface structure and an almost Pt-pure layer, the rest of the slab remaining with the $\mathrm{L}_{2}$ over stoichiometric ordered phase until $80 \%$ of Pt. Then, there is a Pt segregation with an oscillating profile, decreasing as a function of the depth, and all the sublattices are equally occupied to form the disordered bulk phase. The (110) surface structure is schematically represented on Fig. 11 together with the bulk phases.

The $c(2 \times 2)$ is typically a surface alloy since it does not have an equivalent in bulk layers, except in a $\mathrm{DO}_{22}$ phase but which is not stable as compared to the $\mathrm{L}_{2}$ phase for the Co-Pt system. We also notice an important lattice relaxation perpendicularly to the surface which is correlated the surface segregation reversal in the (110) surface.

\section{Conclusions}

We presented a theoretical study of the three low indices surfaces of Co-Pt alloys as an interesting study to foresee the chemical ordering of nanoalloys terminated by (111) and (100) facets. The new parameterization of the TB-SMA interatomic potential, which could apply to a more extended categories of alloys such as $\mathrm{Pt}-\mathrm{Ni}$, represents a family of systems with a pronounced ordering tendency but a weak surface segregation leading to the segregation reversal with a Pt segregation on the compact (111) and (100) surfaces and a Co or Ni segregation on the (110) one. Using Monte Carlo simulations, we studied specifically each infinite surface in the whole range of concentration of the $\mathrm{Co}_{1-c} \mathrm{Pt}_{c}$ alloys at room temperature. The alloy surfaces can present some new 2D surface alloys, especially the $(\sqrt{3} \times \sqrt{3}) \mathrm{R} 30$ on the (111) and the $\mathrm{c}$ (2x2) on the (110), with no equivalent ordering in bulk, but in general the surface structures are essentially a bulk ordered phase termination, as the $\mathrm{p}(2 \times 1)$ and $\mathrm{p}(2 \times 2)$ on the $(111)$ surface or the $\mathrm{p}(2 \times 1)$ (110).

However, the phase transitions occurring at the surfaces, although correlated to the one in the bulk, are not fully trivial: for example on the (100) surface, the surface composition remains constant with the c $(2 \times 2)$ structure on a wide range of bulk concentration whereas the subsurface composition varies as a function of the variation of the off stoichiometry of the ordered phase below. The $\mathrm{c}(2 \times 2)$ structure remains up to the under stoichiometric $\mathrm{CoPt}_{3}$ phase. Then, exactly at the $\mathrm{CoPt}_{3}$ stoichiometric phase, there is an abrupt transition to a Pt-pure surface which coexists with the over stoichiometric $\mathrm{CoPt}_{3}$ phase which becomes disordered when increasing the Pt concentration.

In the (110) surface at low temperature there is a Co-pure surface in the composition range $25-50 \%$ of Pt in the slab, in coexistence with the over stoichiometric $\mathrm{Co}_{3} \mathrm{Pt} \mathrm{L1} 1_{2}$ phase and the under stoichiometric $\mathrm{L} 1_{0}$ one, up to the stoichiometric CoPt surface with an alternation of pure layers. Increasing slightly the Pt concentration, Pt atoms occupy half of the sites of the surface forming the original $c(2 \times 2) 2 \mathrm{D}$ surface ordering in coexistence with the over stoichiometric $\mathrm{CoPt} L 1_{0}$ phase, up to the transition with the $\mathrm{L}_{2}$ under stoichiometric $\mathrm{CoPt}_{3}$ phase with the surface termination forming the $\mathrm{p}(2 \times 1)$. As for the (100) surface, the over stoichiometric $\mathrm{L} 1_{2}$ phase forms a Pt-pure surface layer before the transition towards the solid solution.

Concerning the (111) surface, the situation could have been simple as the four bulk sublattices lie in the surface and we could have observed the succession of the $\mathrm{p}(2 \times 2) \mathrm{Co}_{3} \mathrm{Pt}$, the $\mathrm{p}(2 \times 1)$ CoPt and the $\mathrm{p}(2 \times 2) \mathrm{CoPt}_{3}$ as obtained on a rigid-lattice model [30]. However, in the Co-rich part, the $\mathrm{p}(2 \times 2)$ is not stable, instead we obtain the $(\sqrt{3} \times \sqrt{3})$ R30 in all the composition range of the over stoichiometric $\mathrm{L}_{2} \mathrm{Co}_{3} \mathrm{Pt}$ phase. More surprisingly, the $(\sqrt{3} \times \sqrt{3}) \mathrm{R} 30$ in the Pt-rich domain coexists with both a part of the over stoechiometric $\mathrm{L} 1_{0}$ phase and a part of the under stoichiometric $\mathrm{L}_{2}$ phase. Thus, the transitions from the $\mathrm{p}(2 \times 1)$ to the $(\sqrt{3} \times \sqrt{3}) \mathrm{R} 30$ and then to the $\mathrm{p}(2 \times 2)$ do not correspond to chemical ordering transition in the bulk. This is why we guess it could be driven by surface stress. 
This study suggests new first principle calculations to investigate the stability of the 2D $(\sqrt{3} \times \sqrt{3}) \mathrm{R} 30(111)$ phase as compared to others [64]. We could also include temperature effects in DFT calculations as performed by Reuter and Scheffler [85] to compare different finite temperature structures obtained by TB-SMA Monte Carlo and by the so-called ab initio thermodynamics. We also expect new experimental studies for concentration ranges which were not investigated before. We rely on the extraordinary progress of the transmission electron microscopy with chemical species sensitivity to be able to characterize the facet composition of nanoalloys [46]: $1 / 3$ or $2 / 3$ could be a first indication of the $(\sqrt{3} \times \sqrt{3})$ R30(111) phase as compared to $1 / 4-3 / 4$ for the $\mathrm{L}_{2}$ termination.

Finally, we show for the first time that the CoPt $c(2 \times 2)(100)$ surface remains ordered at higher temperature than the $\mathrm{L} 1_{0}$ bulk phase. This phenomenon could influence the ordering of nanoalloys with (100) facets.

\section{Acknowledgments}

This work was granted access to the HPC resources of IDRIS under the allocation 2017-096829 made by GENCI.

\section{References}

[1] R. Hultgren, P.D. Desai, D.T. Hawkins, M. Gleiser, K.K. Kelley, Selected Values of the Thermodynamic Properties of Binary Alloys, American Society for Metals, Berkeley, Jossey-Bass Publishers, 1981.

[2] C. Leroux, M. Cadeville, V. Pierron-Bohnes, G. Inden, F. Hinz, J. Phys. F 18 (1988) 2033.

[3] J. Sanchez, J. Moran-Lopez, C. Leroux, M. Cadeville, J. Phys. 1 (1989) 491.

[4] C. Leroux, A. Loiseau, A. Broddin, G.V. Tendeloo, Phil. Mag. B 64 (1991) 57.

[5] M. Capitan, S. Lefebvre, Y. Calvayrac, M. Bessière, P. Cénédèse, J. Appl. Cryst. 32 (1999) 1039.

[6] E. Kentzinger, V. Parasote, V. Pierron-Bohnes, J. Lami, M. Cadeville, J. Sanchez, R. Caudron, B. Beuneu, Phys. Rev. B 61 (2000) 14975.

[7] Y. LeBouar, A. Loiseau, A. Finel, F. Ducastelle, Phys. Rev. B 61 (2000) 3317.

[8] Y. LeBouar, A. Loiseau, A. Finel, Phys. Rev. B 68 (2003) 224203.

[9] P. Andreazza, V. Pierron-Bohnes, F. Tournus, C. Andreazza-Vignolle, V. Dupuis, Surf. Sci. Rep. 70 (2015) 188.

[10] M. Jamet, W. Wernsdorfer, C. Thirion, D. Mailly, V. Dupuis, P. Mélinon, A. Pérez, Phys. Rev. Lett. 86 (2001) 4676.

[11] F. Tournus, A. Tamion, N. Blanc, A. Hannour, L. Bardotti, B. Prével, P. Ohresser, E. Bonet, T. Epicier, V. Dupuis, Phys. Rev. B 77 (2008) 144411.

[12] F. Tournus, N. Blanc, A. Tamion, M. Hillenkamp, V. Dupuis, Phys. Rev. B 81 (2010) 220405.

[13] M. Delalande, M.J.-F. Guinel, L.F. Allard, A. Delattre, R. Le Bris, Y. Samson, P. Bayle-Guillemaud, P. Reiss, J. Phys. Chem. C 116 (2012) 6866-6872.

[14] M. Lebedeva, V. Pierron-Bohnes, C. Goyhenex, V. Papaefthimiou, S. Zafeiratos, R. Nazmutdinov, V.D. Costa, M. Acosta, L. Zosiak, R. Kozubski, D. Muller, E. Savinova, Electrochim. Acta 108 (2013) 605.

[15] J. Penuelas, P. Andreazza, C. Andreazza-Vignolle, H.C.N. Tolentino, M. De Santis C. Mottet, Phys. Rev. Lett. 100 (2008) 115502.

[16] P. Andreazza, C. Mottet, C. Andreazza-Vignolle, J. Penuelas, H.C.N. Tolentino, M. De Santis, R. Felici, N. Bouet, Phys. Rev. B 82 (2010) 155453.

[17] L. Favre, V. Dupuis, E. Bernstein, P. Mélinon, A. Pérez, S. Stanescu, T. Epicier, J. P. Simon, D. Babonneau, J.-M. Tonnerre, J.-L. Hodeau, Phys. Rev. B 74 (2006) 014439.

[18] S. Rohart, C. Raufast, L. Favre, E. Bernstein, E. Bonet, V. Dupuis, Phys. Rev. B 74 (2006) 104408.

[19] A. Tamion, M. Hillenkamp, F. Tournus, E. Bonet, V. Dupuis, Appl. Phys. Lett. 95 (2009) 062503.

[20] D. Alloyeau, C. Ricolleau, C. Mottet, T. Oikawa, C. Langlois, Y. Le Bouar, A. Loiseau, Nat. Mater. 8 (2009) 940.

[21] D. Alloyeau, G. Prévot, Y. Le Bouar, T. Oikawa, C. Langlois, A. Loiseau, C. Ricolleau, Phys. Rev. Lett. 105 (2010) 255901.

[22] N. Blanc, F. Tournus, V. Dupuis, T. Epicier, Phys. Rev. B 83 (2011) 092403.

[23] J.-Y. Bigot, H. Kesserwan, V. Haltié, O. Ersen, M. Moldovan, T. Kim, J.-T. Jang, J. Cheon, Nano Lett. 12 (2012) 1189.

[24] F. Tournus, K. Sato, T. Epicier, T. Kono, V. Dupuis, Phys. Rev. Lett. 110 (2013) 055501.

[25] N. Blanc, L.E. Diaz-Sánchez, A.Y. Ramos, F. Tournus, H.C.N. Tolentino, M. De Santis, O. Proux, A. Tamion, J. Tuaillon-Combes, L. Bardotti, O. Boisron, G.M. Pastor, V. Dupuis, Phys. Rev. B 87 (2013) 155412.

[26] M. Gruner, G. Rollmann, P. Entel, M. Farle, Phys. Rev. Lett. 100 (2008) 087203.

[27] G. Barcaro, R. Ferrando, A. Fortunelli, G. Rossi, J. Phys. Chem. Lett. 1 (2010) 111.

[28] J. Montejano-Carrizales, F. Aguilera-Granja, C. Goyhenex, V. Pierron-Bohnes, J. Moran-Lopez, J. Mag. Mag. Mater. 355 (2014) 215.
[29] F. Calvo, C. Mottet, Phys. Rev. B 84 (2011) 035409.

[30] A. Lopes, G. Tréglia, C. Mottet, B. Legrand, Phys. Rev. B 91 (2015) 035407.

[31] R.V. Chepulskii, W.H. Butler, Phys. Rev. B 86 (2012) 155401.

[32] P. Moskovkin, M. Hou, J. Alloys Compd. 434-435 (2007) 550.

[33] C. Goyhenex, H. Bulou, J.-P. Deville, G. Tréglia, Phys. Rev. B 60 (1999) 2781, https://doi.org/10.1103/PhysRevB.60.2781.

[34] G. Rossi, R. Ferrando, C. Mottet, Faraday Discuss. 138 (2008) 193.

[35] M. Baskes, Phys. Rev. B 46 (1992) 2727.

[36] V. Rosato, M. Guillopé, B. Legrand, Phil. Mag. A 59 (1989) 321.

[37] Y. Gauthier, Y. Joly, R. Baudoing, J. Rundgren, Phys. Rev. B 31 (1985) 6216-6218.

[38] Y. Gauthier, R. Baudoing-Savois, J. Bugnard, W. Hebenstreit, M. Schmid, P. Varga, Surf. Sci. 466 (2000) 155 .

[39] Y. Gauthier, R. Baudoing-Savois, J. Bugnard, U. Bardi, A. Atrei, Surf. Sci. 276 (1992) 1.

[40] Y. Gauthier, P. Dolle, R. Baudoing-Savois, W. Hebenstreit, E. Platzgummer, M. Schmid, P. Varga, Surf. Sci. 396 (1998) 137.

[41] U. Bardi, A. Atrei, G. Rovida, E. Zanazzi, P. Ross, Surf. Sci. 211/212 (1989) 441.

[42] U. Bardi, A. Atrei, G. Rovida, E. Zanazzi, P. Ross, Vacuum 41 (1990) 437.

[43] Y. Gauthier, R. Baudoing, M. Lundberg, J. Rundgren, Phys. Rev. B 35 (1987) 7867-7878.

[44] J. Bugnard, R. Baudoing-Savois, Y. Gauthier, E. Hill, Surf. Sci. 281 (1993) 62.

[45] J. Bugnard, Y. Gauthier, R. Baudoing-Savois, Surf. Sci. 344 (1995) 42.

[46] M. Chi, C. Wang, Y. Lei, G. Wang, D. Li, K.L. More, A. Lupini, L. Allard, N. Markovic, V. Stamenkovic, Nat. Com. 6 (2015) 8925.

[47] J. Erlewein, S. Hofmann, Surf. Sci. 68 (1977) 71.

[48] J. Ferrante, Acta Met. 19 (1971) 743.

[49] R. Baird, D. Ogletree, M.V. Hove, G. Somorjai, Surf. Sci. 165 (1986) 345.

[50] M. Galeotti, A. Atrei, U. Bardi, G. Rovida, M. Torrini, Surf. Sci. 313 (1994) 349.

[51] C. Gallis, B. Legrand, G. Tréglia, Surf. Sci. 377-379 (1997) 1033.

[52] E. Soares, C. Bittencourt, E. Lopes, V. de Carvalho, D. Woodruff, Surf. Sci. 550 (2004) 127-132.

[53] M. Lahti, A. Chaudhuri, K. Pussi, D. Hesp, I. McLeod, V. Dhanak, M. King, M. Kadodwala, D. MacLaren, Surf. Sci. 622 (2014) 35.

[54] R. van Gastel, D. Kaminski, E. Vlieg, B. Poelsema, Surf. Sci. 603 (2009) 3292.

[55] Y. Girard, C. Chacon, G. de Abreu, J. Lagoute, V. Repain, S. Rousset, Surf. Sci. 617 (2013) 118.

[56] I. McLeod, V. Dhanak, A. Matilainen, M. Lahti, K. Pussi, K. Zhang, Surf. Sci. 604 (2010) 1395-1399.

[57] D. Brown, P.D. Quinn, D.P. Woodruff, P. Bailey, T.C.Q. Noakes, Phys. Rev. B 61 (2000) 7706-7715, https://doi.org/10.1103/PhysRevB.61.7706.

[58] J. Dalmas, H. Oughaddou, C. Léandri, J.-M. Gay, G. Le Lay, G. Tréglia, B. Aufray, O. Bunk, R.L. Johnson, Phys. Rev. B 72 (2005) 155424.

[59] J. Dalmas, H. Oughaddou, G.L. Lay, B. Aufray, G. Tréglia, C. Girardeaux, J.B. ardini, J. Fujii, G. Panaccione, Surf. Sci. 600 (2006) 1227-1230.

[60] I.M. McLeod, V.R. Dhanak, M. Lahti, A. Matilainen, K. Pussi, K.H.L. Zhang, J. Phys.: Condens. Matter 23 (2011) 265006.

[61] B. Zhu, H. Guesmi, J. Creuze, B. Legrand, C. Mottet, Phys. Chem. Chem. Phys. 17 (2015) 28129.

[62] F.R. de. Boer, Cohesion in Metals: Transition Metal Alloys, (1988). Amsterdam: North-Holland

[63] V.A. de la Pe OShea, I. de P. R. Moreira, A. Roldn, F. Illas, J. Chem. Phys. 133 (2010) 024701.

[64] A. Dannenberg, M.E. Gruner, A. Hucht, P. Entel, Phys. Rev. B 80 (2009) 245438.

[65] J.P. Perdew, Y. Wang, Phys. Rev. B 45 (1992) 13244-13249.

[66] P.E. Blöchl, Phys. Rev. B 50 (1994) 17953-17979.

[67] G. Kresse, D. Joubert, Phys. Rev. B 59 (1999) 1758-1775.

[68] J.P. Perdew, K. Burke, M. Ernzerhof, Phys. Rev. Lett. 77 (1996) 3865-3868, https:// doi.org/10.1103/PhysRevLett.77.3865.

[69] P. Janthon, S.M. Kozlov, F. Vines, J. Limtrakul, F. Illas, J. Chem. Theory Comput. 9 (2013) 1631

[70] P. Janthon, S.A. Luo, S.M. Kozlov, F. Vines, J. Limtrakul, D.G. Truhlar, F. Illas, J. Chem. Theory Comput. 10 (2014) 3832.

[71] L. Vega, J. Ruvireta, F. Vines, F. Illas, J. Chem. Theory Comput. 14 (2018) 395.

[72] S. Karoui, H. Amara, B. Legrand, F. Ducastelle, J. Phys. 25 (2013) 056005.

[73] G. Tréglia, B. Legrand, F. Ducastelle, A. Saul, C. Gallis, I. Meunier, C. Mottet, A. Senhaji, Comput. Mater. Sci. 15 (1999) 196-235.

[74] N. Metropolis, A. Metropolis, M. Rosenbluth, A. Teller, E. Teller, J. Chem. Phys. 21 (1953) 1087.

[75] M. Lundberg, Phys. Rev. B 36 (1987) 4692-4699.

[76] I.A. Abrikosov, A.V. Ruban, H.L. Skriver, B. Johansson, Phys. Rev. B 50 (1994) 2039-2042.

[77] B. Legrand, G. Tréglia, F. Ducastelle, Phys. Rev. B 41 (1990) 4422.

[78] M. Paffett, R. Windham, Surf. Sci. 208 (1989) 34.

[79] S. Overbury, D. Mullins, M. Paffett, B. Koel, Surf. Sci. 254 (1991) 45.

[80] C. Gallis, Thesis, CEA/Saclay (1997).

[81] S. de Vries, W. Huisman, P. Goedtkindt, M. Zwanenburg, S. Bennett, I. Robinson, E. Vlieg, Surf. Sci. 414 (1998) 159.

[82] Y. Teraoka, Surf. Sci. 235 (1990) 249.

[83] J.L. Morán-López, K.H. Bennemann, Phys. Rev. B 15 (1977) 4769-4780.

[84] F. Mejía-Lira, K.H. Bennemann, J.L. Morán-López, Phys. Rev. B 32 (1985) 5925-5931.

[85] K. Reuter, M. Scheffler, Phys. Rev. B 65 (2001) 035406, https://doi.org/10.1103/ PhysRevB.65.035406. 